\title{
Combining Music and Indoor Spatial Factors Helps to Improve College Students' Emotion During Communication
}

\author{
Jiani Jiang, Qi Meng* and Jingtao Ji
}

Key Laboratory of Cold Region Urban and Rural Human Settlement Environment Science and Technology, Ministry of Industry and Information Technology, School of Architecture, Harbin Institute of Technology, Harbin, China

Against the background of weakening face-to-face social interaction, the mental health of college students deserves attention. There are few existing studies on the impact of audiovisual interaction on interactive behavior, especially emotional perception in specific spaces. This study aims to indicate whether the perception of one's music environment

OPEN ACCESS

Edited by:

Francesco Aletta,

University College London,

United Kingdom

Reviewed by:

Andre Fiebig,

Technical University of Berlin,

Germany

Simone Torresin,

University of Trento, Italy

*Correspondence:

Qi Meng

mengq@hit.edu.cn

Specialty section:

This article was submitted to

Environmental Psychology,

a section of the journal

Frontiers in Psychology

Received: 18 May 2021

Accepted: 10 August 2021

Published: 14 September 2021

Citation:

Jiang J, Meng Q and Ji J (2021)

Combining Music and Indoor Spatial

Factors Helps to Improve College

Students' Emotion During Communication.

Front. Psychol. 12:703908.

doi: 10.3389/fpsyg.2021.703908 has influence on college students' emotion during communication in different indoor conditions including spatial function, visual and sound atmospheres, and interior furnishings. The three-dimensional pleasure-arousal-dominance (PAD) emotional model was used to evaluate the changes of emotions before and after communication. An acoustic environmental measurement was performed and the evaluations of emotion during communication was investigated by a questionnaire survey with 331 participants at six experimental sites [including a classroom (CR), a learning corridor (LC), a coffee shop (CS), a fast food restaurant (FFR), a dormitory (DT), and a living room(LR)], the following results were found: Firstly, the results in different functional spaces showed no significant effect of music on communication or emotional states during communication. Secondly, the average score of the musical evaluation was 1.09 higher in the warm-toned space compared to the cold-toned space. Thirdly, the differences in the effects of music on emotion during communication in different sound environments were significant and pleasure, arousal, and dominance could be efficiently enhanced by music in the quiet space. Fourthly, dominance was 0.63 higher in the minimally furnished space. Finally, we also investigated influence of social characteristics on the effect of music on communication in different indoor spaces, in terms of the intimacy level, the gender combination, and the group size. For instance, when there are more than two communicators in the dining space, pleasure and arousal can be efficiently enhanced by music. This study shows that combining the sound environment with spatial factors (for example, the visual and sound atmosphere) and the interior furnishings can be an effective design strategy for promoting social interaction in indoor spaces.

Keywords: social interaction, college students, audiovisual interaction, music, emotion during communication, pleasure-arousal-dominance emotional state model, spatial factors, social characteristics 


\section{INTRODUCTION}

There has been a weakening of social interaction among contemporary college students, many of whom prefer chatting online as opposed to face-to-face communication. According to The 47th China statistical report on Internet Development (2021), by December 2020, netizens aged 20-29 accounted for $17.8 \%$ of total users, and students accounted for the highest proportion in the occupational structure. College is a period characterized by dynamic development of the brain and strong interactions within the social environment. Students are vulnerable to a range of psychological problems; three-quarters of cases of four common mental disorders begin between the ages of 20 and 30 (Patel et al., 2007; Mirón et al., 2019). Research has shown that social anxiety is a significant and common issue for college students, given the growing range of academic and social stressors (Evans et al., 2018; Yang et al., 2019). Addiction to online networks can impair social activities, work/study, interpersonal relationships, and/or psychological health and well-being (Andreassen and Pallesen, 2014), and significant amounts of screen time correlate with both depression and anxiety (Lin et al., 2016; Rosenthal et al., 2021). As good interpersonal communication ability is one of the most important qualities of college students, the use of architectural design to improve communication spaces and promote interaction is of great significance. However, architectural methods of promoting communicative behavior have so far remained at the level of spatial design and have neglected the architectural sound environment.

Human actions, particularly in face-to-face encounters, invite responsive behaviors that include variations in wording, stress, volume, tone of voice, gesture, gaze, head movements, and even breathing patterns (Jensen and Pedersen, 2016). The social interaction model indicates that senders' displays of emotion provide powerful signals to receivers during interpersonal interactions, which people are hard-wired to pick up on and then rely on to guide their own behavior (Côté, 2005). Furthermore, interpersonal relationships can be fulfilled by emotions (Wubben et al., 2009). Authentic displays of some emotions - for instance, happiness - communicate an intention to affiliate and indicate that the individual is friendly and agreeable (Côté, 2005). The concept of emotional contagion (Hatfield et al., 1993) entails a ripple effect (also known as an imitation effect) of human interaction through conscious or unconscious induction of emotional states and behavioral attitudes (Hess and Blairy, 2001). For instance, negative emotions, especially anger, can often lead to violence (Umberson et al., 2003); conversely, regarding positive emotions, positive correlations have been found between the total amount of face-to-face interaction and the interlocutors' resulting mood (Ono et al., 2012). Communication is a fundamental part of social face-to-face interaction that can produce cooperation or coordination (Olguin et al., 2009). However, there is insufficient research focusing on how to balance emotions during communication in combination with the sound environment.

Previous studies have shown that emotion can be affected by environmental contexts ( $\mathrm{Li}$ et al., 2012; Lazarus, 2014), including luminous, thermal, and acoustic factors. In terms of acoustic perception, the soundscape is defined as a sonic environment, with an emphasis on the way it is perceived and understood by individuals or by society (Brown et al., 2011). Evaluations of stimuli indicate that human emotions track changes in environmental sounds, especially in speech and music (Ma and Thompson, 2016). As a specific sound source, music has been found to be beneficial for rewards, motivation, pleasure, stress, arousal, immunity, and social affiliations (Juslin and Västfäll, 2008; Chanda and Levitin, 2013). Evidence against a strict cognitivist position suggests that music can induce some sort of emotional response (Hunter and Schellenberg, 2010), which can be categorized as one of the nine common emotions of wonder, transcendence, tenderness, sadness, nostalgia, peacefulness, power, joy, and tension (Huron, 2011). Previous studies have found a modulation of the activities of the brain's core structures ascribed to emotion processing by music, involving the amygdala and the hippocampus, which are central elements in the network that process emotions such as happiness, anxiety, anger, and annoyance, as well as for assessing facial expressions and thereby contributing to communication, social behavior, and memory (Koelsch and Skouras, 2014; Hans-Eckhardt, 2017). For instance, music can lead to emotional contagion; happy music triggers the zygomatic muscle for smiling, together with an increase in skin conductance and breathing rate, whereas sad music activates the corrugator muscle (Koelsch, 2014). Despite these valuable findings, most research on music-evoked emotion has been conducted under laboratory conditions without taking into account the broader context, including spatial conditions and the physical environment. In addition, most studies have focused on the individual emotional state to the neglect of social interactions in specific patterns of behavior.

Being physically, emotionally, and psychologically aware of the space, we occupy is a feeling that can be described as being present. Jürgen Joedicke noted the need to take into consideration, the experience of space as well as spatial perception (Vasilski, 2016). Indoor space is the main site for human activities. Interaction between people and their located environment, like social interaction, is spontaneous and unavoidable, and the specific psychological emotions evoked by the physical and environmental attributes of personal interior space offer a highly interesting topic for research (Reddy et al., 2012). Interrelated elements of interior design, including spatial form, structure, light, texture, and color, as well as environmental factors such as lighting, sound, temperature, and humidity, affect spatial atmosphere and emotion (Reddy et al., 2012).

Taking spatial form as an example, a study of the impact of office design on absence rates has shown that stress levels and sick leave rates are higher in traditional open-plan offices than in cell-offices or combi-offices (Danielsson et al., 2014). Numerous studies have also examined the effects of light on emotion. For instance, the use in accent lighting of saturated blue and cyan colors with a color temperature of 5,000-5,500 K has been found to lead to the emotion of liveliness (Kim and Mansfield, 2021). In terms of color, red is likely to be stimulating because it increases blood pressure and heart rate (Manav, 2017). 
Natural communication is dynamic in nature, hence the importance of investigating the audiovisual effects of space on social interaction (Boer et al., 2018). However, most studies of emotional perception have relied on the visual factors of spaces and ignored the combined sound environment.

Previous work in a classroom context analyzing the effects of music on conversational interaction has shown that, to a certain degree, musical sound has a masking effect on other noises and promotes communication in general (Jiang et al., 2019). Here, emotion during communication refers to changes in emotion following communication compared to the original emotional state before communication. The study utilizes the three-dimensional pleasure-arousal-dominance (PAD) emotional model to assess the emotions of participants through three dimensions of pleasure, arousal, and dominance before and after communication. The difference values ( $d$-values) of pleasure, arousal, and dominance are used to reflect the changes in emotion during communication. To investigate differences in the effects of music on emotion during communication at different sites, this study sets out four hypotheses.

Hypothesis 1: is that the effects of music on emotion during communication vary in spaces with different functions.

Hypothesis 2: is that visual atmosphere influences the effects of music on emotion during communication.

Hypothesis 3: is that the sound atmosphere influences the effects of music on emotion during communication.

Hypothesis 4: is that interior furnishings serve as an influential spatial factor that moderate the effects of music on communication.

Hypothesis 5: is that the effects of music on emotion during communication differ when participants are subject to different social characteristics, including the intimacy level, gender combination, and group size.

\section{METHODOLOGY}

\section{Experimental Site}

There are two main kinds of emotion-related experiments: field experiments and laboratory experiments. On the basis of reliability and authenticity (Harrison, 2003), in this study, a field experiment was conducted in different sites, respectively, under the same musical environment. In terms of the selection of experimental sites, the location and time to confront people (especially strangers) can significantly influence the communication that takes place (Weisburd, 2021). In order to avoid any influence of familiarity with the space on communication (Krupa et al., 2018), indoor places frequently visited by students were chosen for this study. In line with common student activities, experimental sites were classified into learning, dining, and residential spaces based on spatial functions (Boukhechba et al., 2018). In order to explore the influence of qualities-related factors on emotion (Maheshwari et al., 2019), such as visual and sound atmospheres, as well as interior furnishings, six typical indoor communication spaces were chosen as the experimental sites and were compared one by one based on their functional classification: classroom (CR), learning corridor (LC), coffee shop (CS), fast food restaurant (FFR), dormitory (DT), and living room (LR). Indoor layouts of the experimental sites are shown in Figures 1A-F. LC here refers to a corridor containing a learning space as shown in Figure 1. Tables and chairs arranged in the learning space are used for students' daily reading and communication. And, it is worth mentioning that the learning space (CR, LC) discussed in this study is used for students' self-study (not teaching), including learning communication and chat.

In terms of behavior mode, the $\mathrm{CR}$ and $\mathrm{LC}$ are used for self-study, and typical behaviors in these areas include learning communication and daily chat; the CS is frequently visited by students for socializing and tea breaks; FFR is a popular location for dining; and the DT (four-person) and LR in residence halls comprise the main living areas for college students, wherein typical behaviors include rest, leisure, and socializing.

A thermal measurement instrument and illuminance meter were used to ensure that indoor temperature and illumination were within the comfort range, and therefore, not likely to influence emotion or performance (Altomonte, 2017; Petersen and Knudsen, 2017). In terms of thermal factors, related experimental results have shown that performance improves as the indoor temperature approaches $23^{\circ} \mathrm{C}$ (Nematchoua et al., 2019) and decreases when the temperature rises above $25^{\circ} \mathrm{C}$ (Niemelä et al., 2002). Therefore, the experiment time was set from $9 \mathrm{a} . \mathrm{m}$. to $4 \mathrm{p} . \mathrm{m}$. to maintain the indoor temperature at $23-25^{\circ} \mathrm{C}$. In terms of luminous factors, previous studies have shown that illuminance and light color can affect fatigue and emotion (Carlucci et al., 2015). Preferred illuminance was therefore set in the range of 310-600lux, and a neutral white $(4,000 \mathrm{~K})$ space was used (Bowers et al., 2010; Hidayetoglu et al., 2012; Yang and Moon, 2018). Since it was difficult to maintain the same illuminance on all six sites, neutral white $(4,000 \mathrm{~K})$ light was used to decrease the effects of the light environment, and lamps in the room maintained an average illuminance of 310-600 lux.

Sound level meters (BSWA801, BSWA, Beijing, China) were located at the measurement points shown in Figure $\mathbf{1}$ and at a height of $1.2 \mathrm{~m}$ from the ground, and provided multiple measures of the background sound pressure level (SPL) at each of the six experimental sites for $5 \mathrm{~min}$ per hour from 9 a.m. to 4 p.m., with recordings every $5 \mathrm{~s}$, which were A-weighted in the uncontrolled condition without subjects (Torija et al., 2012). In addition, because the experimental behavior was face-to-face communication, reverberation time (RT) was a significant factor influencing speech intelligibility (Yang and Hodgson, 2006), which may influence the quality of communication. Therefore, using the Eyring formula (Passero and Zannin, 2010), the RT of each experimental site was calculated, including the absorption coefficient, area, and amount. 
A

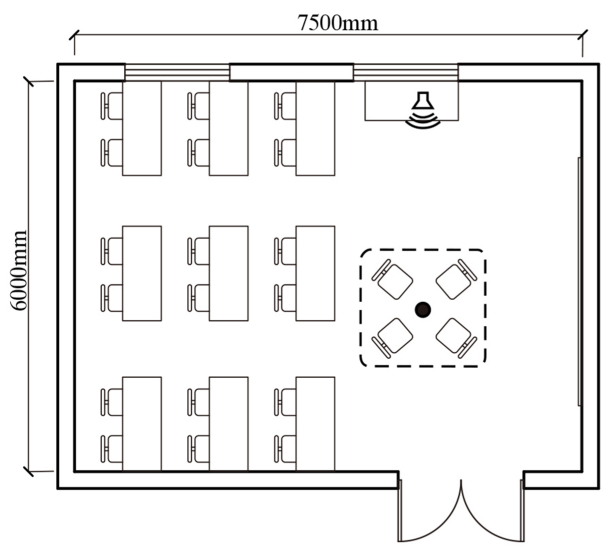

๑))) Sound Source

I_ I Communication Location

Measuring Point

B

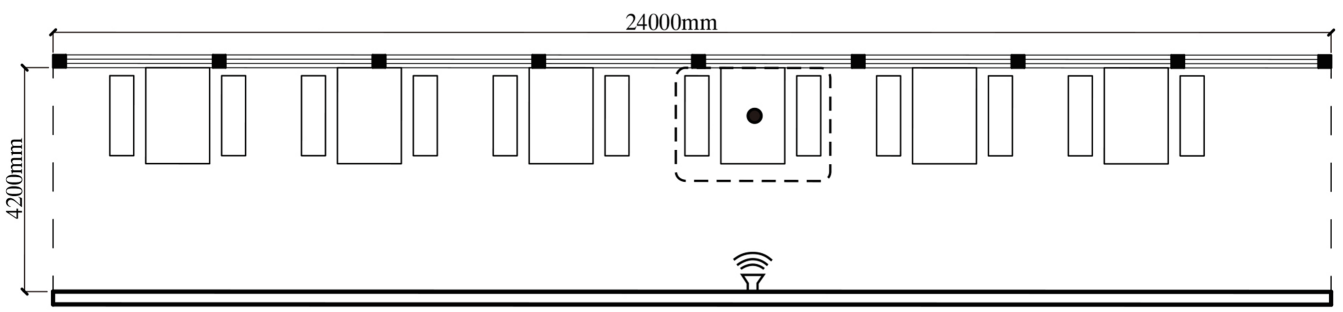

C

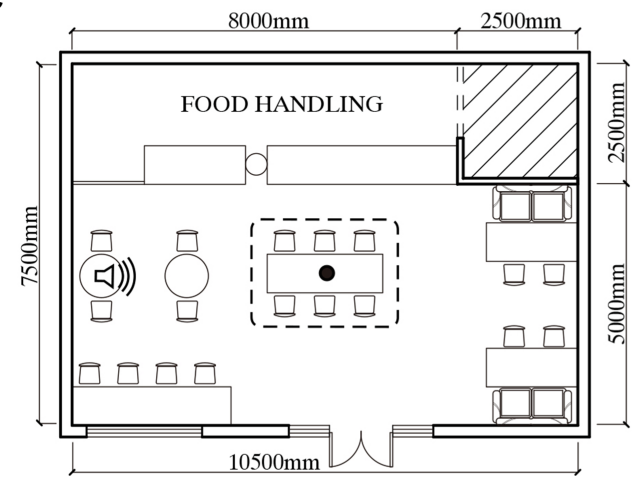

E

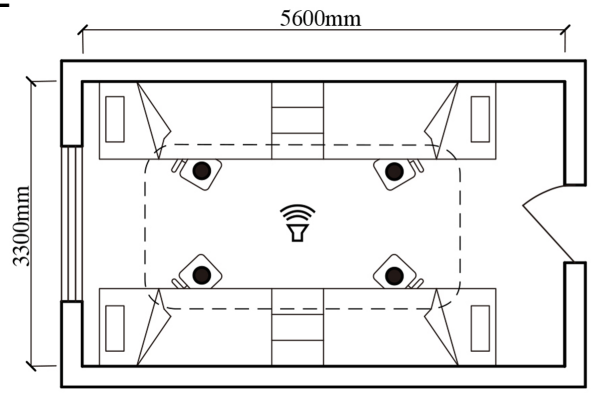

D

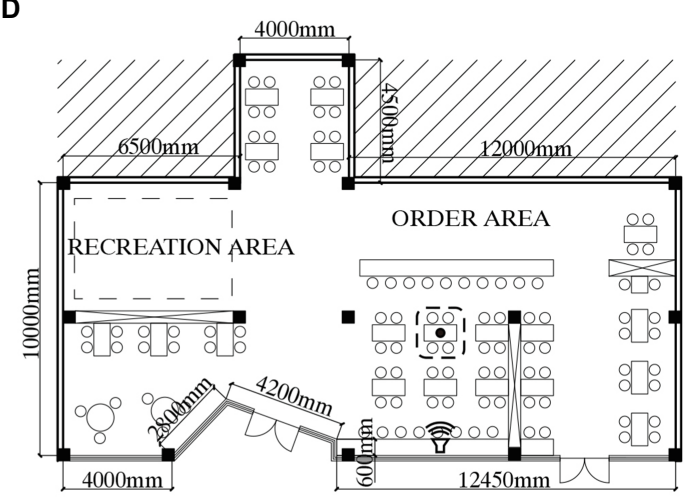

$\mathbf{F}$

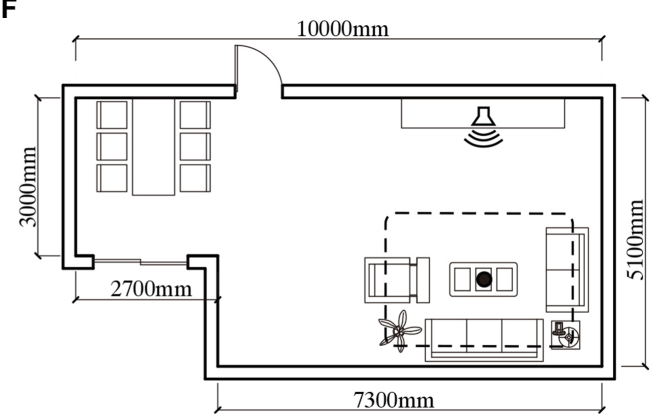

FIGURE 1 | Indoor layouts of the experimental sites: (A) CR, classroom; (B) LC, learning corridor; (C) CS, coffee shop; (D) FFR, fast food restaurant; (E) DT, dormitory; and (F) LR, living room.

The characteristics of the experimental sites, including scale, background SPL, RT, and behavior patterns, are shown in Table 1. The data show that the average A-weighted equivalent
SPL for $5 \mathrm{~min}$ of background sound recording at the measurement point ranged from 32.5 to $63.2 \mathrm{dBA}$ at the six sites, among which, under the same spatial function, the difference in SPL 
was largest (25.3 dBA) between the FFR and the CS. The sensitivity of the instrument was $\pm 0.5 \mathrm{dBA}$. In addition, the average RT value at each site with $2-5$ participants was provided.

\section{Experimental Music}

Previous research indicates that tempo, SPL, and musical emotions may also influence emotion (Hunter and Schellenberg, 2010); this phenomenon that has been assessed using behavioral, physiological, and neurological measures (Koneni, 2008). In terms of tempo, fast music can increase brain activity (Nicolaou et al., 2017). To avoid interference from the high arousal effect of music on the differences between spatial types, slow music was used in this study. Music with high SPL can also increase perceived activation and tension (Olsen et al., 2015). Excluding the FFR, the background SPLs of the other five sites were all below $40 \mathrm{dBA}$; in order to ensure the masking effect of music as well as the sound comfort (Jiang et al., 2019; Meng et al., 2020), an SPL of 50 dBA was adopted for the present study.

Musical emotional characteristics can be classified in terms of musical dimensions, such as pitch height, loudness, timbre, tempo, and intensity (Goshvarpour et al., 2017), and grouped into synonym clusters, such as happiness, sadness, fear, and neutral (Paquette et al., 2018). Related studies have shown that peacefulness is a complex emotion that overlaps with each quadrant of a circumplex model defined by the dimensions of arousal and valence (Hunter and Schellenberg, 2010) without clear emotional directivity. Thus, taking into account the evaluation of familiarity and liking by the college students (Meng et al., 2020), A Comme Amour (slow tempo, peaceful, 50 dBA, high degree of familiarity and liking) was chosen on the basis of restricted gene expression programming (Zhang and Sun, 2013) as the experimental music in this study. As the CR had the lowest background SPL of the six sites, the SPL of the experimental music was measured there. Under the condition with music, measurements were taken three times for $5 \mathrm{~min}$ each time, at 1-min intervals, with readings every $1 \mathrm{~s}$, which were A-weighted (Crandell et al., 2004). Readings for the three times were averaged and recorded. To ensure the accuracy of the musical SPL, the volume of music was adjusted until the average reading of musical SPL reached $50 \mathrm{dBA}$ (actual data $49.66 \pm 0.5 \mathrm{dBA}$, denoted in what follows as $50 \mathrm{dBA})$.

\section{Participants}

In order to avoid the effect of identities and expectations on participants' satisfaction with communication, all participants were graduate students or undergraduate students of the university (Gudykunst and Shapiro, 1996). Further, to avoid potential confounding effects of formal training in music (Gabrielsson, 2002), all participants were non-music majors and had never undergone formal training in music. Before starting the experiment, participants were asked to maintain their emotional stability, obtain sufficient sleep, and follow the same routine as they would during the survey period, without any interference from other events such as exams or parties. To ensure adequate statistical power, $G^{\star}$ Power (a general power analysis program) was used to analyze the minimum sample size of subjects, assuming an effect size of $d=0.5, \alpha=0.05$ and Power $(1-\beta)=0.8$. To answer the main research question regarding the differences between different indoor spaces, the minimum average required sample size was 51 for the student's $t$-test (between-group) and 53 for one-way ANOVA (between-group) when there were three groups. Information about the participants is given in Table 2. Of students in the sample, 55 participated in the CR, 55 in the LC, 52 in the CS, 59 in the FFR, 54 in the DT, and 56 in the LR.

\section{Emotional Model}

Recognition and analysis of human emotions have been researched extensively in neuroscience, psychology, cognitive science, and computer science. Mainstream research on human emotion has focused on facial and vocal expressions (Gunes and Pantic, 2010). In terms of the models of perceived affective quality on soundscapes, Ma et al. (2018) illustrated the feasibility of the semantic differential method (SDM) for measuring human perceptions of sound. The quantitative measurements of the subjective meaning of things were obtained from the subjects' ratings on the bipolar adjective pairs (APs) formed by descriptors with two opposite meanings (Ma et al., 2018). The APs provided a general picture of human perceptions of the tested objects and facilitated comparison between the objects (Ma et al., 2018). Besides, Torresin et al. (2020) indicated that many of perceptional dimensions in complex acoustic environments (i.e., multiple sound types) could be coherently explained under Russel's circumplex model of affect. In order to indicate the audiovisual effects of music and spatial factors on emotion, an emotional model based on the SDM evaluation system describing emotional states was chosen in this study. The discrete emotional model and the dimensional emotion model are the most widely used models that can effectively express

TABLE 1 | Basic spatial and acoustic information of six experimental sites.

\begin{tabular}{|c|c|c|c|c|c|c|}
\hline $\begin{array}{l}\text { Experimental } \\
\text { site }\end{array}$ & $\begin{array}{c}\text { Indoor } \\
\text { area }\left(\mathbf{m}^{2}\right)\end{array}$ & $\begin{array}{c}\text { Floor } \\
\text { height }(\mathrm{m})\end{array}$ & Color scheme & $\begin{array}{l}\text { Background } \\
\text { SPL (dBA) }\end{array}$ & RT (s) & Behavior mode \\
\hline CR & 45 & 3.5 & White, Wooden, and Gray & 32.5 & 1.16 & Learning, chatting \\
\hline LC & 100 & 3.0 & White, Dark, and Gray & 36.7 & 1.54 & Learning, chatting, and walking \\
\hline $\mathrm{CS}$ & 72 & 3.0 & White, Wooden, and Yellow & 37.9 & 1.22 & Dining, chatting, and dating \\
\hline FFR & 235 & 3.5 & White, Wooden, and Red & 63.2 & 1.41 & Dining, chatting \\
\hline DT & 18 & 3.3 & White, Wooden, and Blue & 33.9 & 0.71 & Sleeping, learning, and chatting \\
\hline LR & 45 & 2.8 & White, Wooden, and Gray & 35.6 & 0.91 & Resting, chatting \\
\hline
\end{tabular}


TABLE 2 | Basic information on participants by experimental site.

\begin{tabular}{|c|c|c|c|c|c|}
\hline Experimental site & Total sample size & Gender & Sample size & Mean age & SD of age \\
\hline \multirow{2}{*}{ CR } & \multirow{2}{*}{55} & Male & 27 & 23.96 & 1.48 \\
\hline & & Female & 28 & 23.75 & 1.71 \\
\hline \multirow{2}{*}{ LC } & \multirow{2}{*}{55} & Male & 26 & 23.62 & 2.74 \\
\hline & & Female & 29 & 23.14 & 2.46 \\
\hline \multirow{2}{*}{ CS } & \multirow{2}{*}{52} & Male & 22 & 24.45 & 1.99 \\
\hline & & Female & 30 & 24.20 & 1.95 \\
\hline \multirow{2}{*}{ FFR } & \multirow{2}{*}{59} & Male & 24 & 24.54 & 3.79 \\
\hline & & Female & 35 & 24.14 & 2.56 \\
\hline \multirow{2}{*}{ DT } & \multirow{2}{*}{54} & Male & 27 & 24.48 & 1.83 \\
\hline & & Female & 27 & 24.70 & 0.95 \\
\hline \multirow{2}{*}{ LR } & \multirow{2}{*}{56} & Male & 25 & 24.56 & 1.53 \\
\hline & & Female & 31 & 24.48 & 1.41 \\
\hline
\end{tabular}

and quantify emotion. The discrete emotion model applies emotional labels (e.g., happiness, sadness, surprise, fear, anger, and disgust), although, a single label may not reflect the complexity of the affective state conveyed by such rich sources of information (Gunes and Pantic, 2010). Instead of applying discrete categories of emotion, the dimensional emotional model analyzes and interprets the subtlety, complexity, and continuity of affective behavior in terms of latent dimensions (Havlena et al., 2010). Compared to a two-dimensional scheme - for example, arousal-valence space model of Thayer and Mcnally (1992) - the three-dimensional solution is more informative and helps to differentiate between what the cluster analysis suggests are separate basic-emotion categories (Shaver et al., 1987). Therefore, three-dimensional PAD emotional model of Mehrabian and Russell (1974) was selected for use in this study. The PAD emotional model consists of three APs, including pleasure-displeasure $(\mathrm{P})$, arousal-nonarousal (A), and dominance-submissiveness (D), among which $P$ is defined as positive vs. negative affective states, with higher evaluations of stimuli being associated with greater pleasure induced by the stimuli; A equates to judgments of high-low stimulus activity, which is defined in terms of the level of mental alertness and physical activity; and D is defined as a feeling of control and influence over one's surroundings and others vs. feeling controlled or influenced by situations and others (Mehrabian, 1996; Zhang et al., 2007). Gärling et al. (2020) proposed that self-reports on momentary states (e.g., "How do you feel right now?") in the context of emotional well-being are valid and reliable. In the current study, considering differences in the emotional states of the participants before the experiment, the PAD three-dimensional evaluation was conducted before and after the communication, respectively, and $d$-values of pleasure, arousal, and dominance were used to reflect changes in emotion during communication.

\section{Questionnaire Design}

A questionnaire was used to evaluate the participants' emotional state with a high level of reliability, because self-reports have been found to be an appropriate and natural method for studying emotional responses to music (Gabrielsson, 2002). The questionnaire consisted of four parts: basic information, overall music evaluation, overall spatial evaluation, and emotion during communication before and after the experiment (based on the three-dimensional PAD emotional model). The structure and descriptions of questionnaire are shown in Table 3; among them, overall musical evaluation represents the effect of music on communication and indicates participants' preference regarding the presence of music at different sites during communication. Overall spatial evaluation is composed of four spatial factors: spatial scale, perceived spatial color, sound atmosphere, and interior furnishings. Emotion during communication is evaluated from three dimensions: pleasure, arousal, and dominance. The $d$-values of pleasure, arousal, and dominance before and after the experiments are used to reflect the change in emotion during communication.

\section{Experimental Design}

In order to explore the effects of different spatial types on emotion during communication against a background of music, experiments were conducted in six typical indoor spaces. In terms of experimental means, random assignment, which has high internal validity (Morgan et al., 2000), was used to eliminate systematic differences between the treatment and control groups. Participants recruited on campus were allocated at random to groups of 2-5 people in each conversation. In addition, three levels of communicator intimacy were delineated, including stranger (all sites except DR and LR), acquaintance (all sites), and close friend (all sites). Because the background SPL was different at each of the six sites, to ensure a consistent musical environment, A Comme Amour (50 dBA) as measured in the classroom was played at the same volume at each of the six sites to ensure the sound pressure of the music was same at each indoor space. In terms of the duration of communication, previous studies have found $5 \mathrm{~min}$ to be appropriate for an analysis of communication using average and minimum chatting times (Yamaguchi et al., 2012). To avoid duration affecting people's focused attention and emotion during communication (Dong and Wyer, 2014), each communication period was limited to $5 \mathrm{~min}$. The need for participants to communicate with strangers for 5 min was mentioned when recruiting the volunteers, so that we could ensure all of 
TABLE 3 | The structure and descriptions of questionnaire.

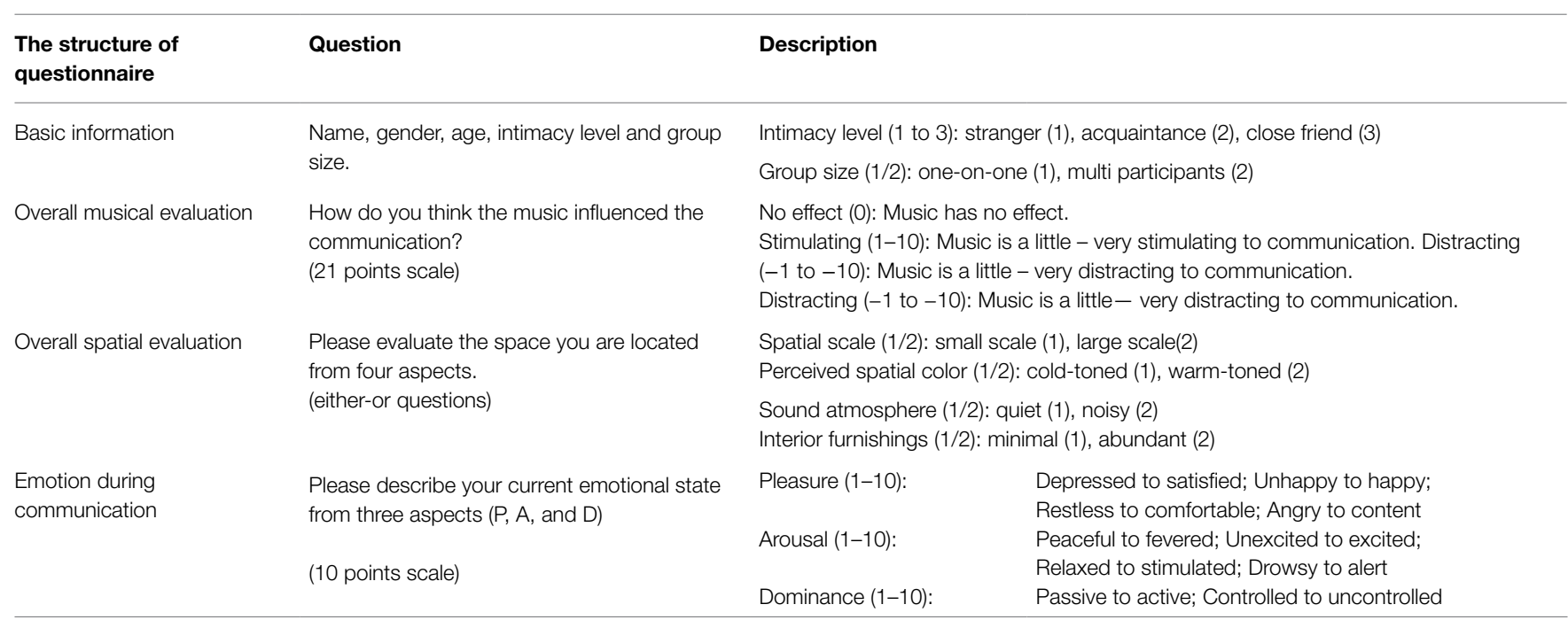

the participants showed a strong desire to conduct conversations with others, including strangers. In addition, participants' post-experiment feedback showed that interactions felt natural and fluent rather than artificial.

The flow chart of the experiment is shown in Figure 2. Following the random allocation, participants entered the experiment room and took around 2-3 min to get familiar with the experimental environment and the people they would talk to. Then, questionnaires were distributed, and participants were required to fill in their basic information according to the instructions in 2-3 min. Participants then began to communicate in the music environment, and continued chatting for $5 \mathrm{~min}$ until the music stopped. During the communication session, considering that participants were strangers, in order to avoid embarrassment several topics were provided for participants to discuss. Participants selected the conversation topics themselves and were then required to complete the questionnaires within $3 \mathrm{~min}$, after which the experiment was deemed complete. In addition, some studies have indicated that food may facilitate communication (Dabbs and Janis, 1965; Blouin et al., 2013); therefore, snacks and nonalcoholic beverages were provided in this study.

Regarding the between-subjects design, in terms of spatial function CR, CS, and LR were chosen for comparison. Because the difference in indoor area of these three sites was within $27 \mathrm{~m}^{2}$, the background SPLs were all below $40 \mathrm{dBA}$, and the colors of the spaces were all warm-toned, the effect of spatial scale and visual and sound environment was deemed minimal. In terms of visual atmosphere, the colors of the LC were cold-toned, which was different from the other spaces. Thus, in order to ensure consistency in the spatial function, CR and LC were chosen for comparison. In terms of sound atmosphere, excluding FFR, the background SPLs of the other five sites were all below $40 \mathrm{dBA}$; thus, in order explore the effect of sound atmosphere of the same functional spaces on communication, CS was chosen for comparison with FFR.

\section{Statistical Methods}

IBM SPSS statistics for Windows, version 23.0 (IBM Corp., Armonk, NY, United States) was used to analyze the relationship between the effects of music on communication and specific spatial factors. The Kolmogorov-Smirnov test was used to analyze the normality of the experimental data - that is, to confirm that the population followed a normal distribution hypothesis. Levene's test was used for equality of variance, and all variance was found to be equal. According to the number of treatments, ANOVA was used to test for significant differences in spaces with different functions (between-group). Independent $t$-tests were performed to assess differences between spaces with different visual and sound atmospheres and interior furnishings.

\section{RESULTS}

Spatial characteristics are expected to affect the use and feeling of a space, and even the emotions experienced during communication therein. This section presents the results of the analysis of the relationships between the spatial factors and the musical evaluations, average evaluation scores and $d$-values for PAD emotional evaluations in terms of spatial function, visual atmosphere, sound atmosphere, and interior furnishings.

\section{Spatial Function}

The experimental sites were sorted into three groups according to function (learning spaces, dining spaces, and residential spaces). CR, CS, and LR (all of which were quiet and had a similar indoor area) were chosen for comparison. The relationships between spatial functions and musical evaluations (no effect/stimulating/distracting) and the average scores for musical evaluations are shown in Figure 3A. The percentage who evaluated the music as stimulating to communication 


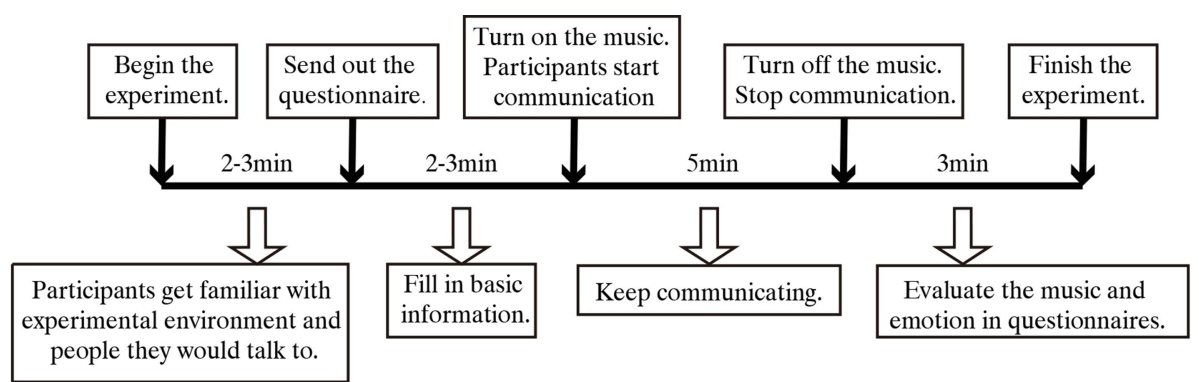

FIGURE 2 | Experimental procedure.

ranged from 52 to $64 \%$ and was highest in the residential space. The percentage evaluating the music as distracting ranged from 7 to $20 \%$ and was highest in the learning space. Average scores for musical evaluation were highest in the residential space (2.91), followed by the dining space, and then the learning space (1.47). Based on the three kinds of spatial functions, the results of the ANOVA show that there was no significant difference in musical evaluation among spaces of different functions $(d f 1=2, d f 2=162, F=2.225$, $p=0.111, d=0.26)$.

The average $d$-values for the PAD emotional evaluations in spaces of different functions are shown in Figure 3B. Pleasure, arousal, and dominance increased to varying degrees, and the $d$-values of pleasure and dominance were similar across the three spaces. Pleasure increased from 0.26 to 0.39 and was highest in the residential space, whereas dominance increased from 0.64 to 0.78 and was highest in the dining space. The $d$-value for arousal was lowest in the learning space (0.53). The results of the ANOVA show that there were no significant effects of different spatial functions on pleasure $(d f 1=2, d f 2=162$, $F=0.061, p=0.941, d=0.05)$, arousal $(d f 1=2, d f 2=162, F=1.309$, $p=0.273, d=0.27)$, or dominance $(d f 1=2, d f 2=162, F=0.070$, $p=0.933, d=0.05$ ).

\section{Visual Atmosphere}

In accordance with subjective evaluations of perceived space color, the experimental sites were grouped into cold-toned spaces and warm-toned spaces. CR and LC (which were both quiet and of learning function but had a clear difference in color evaluation) were chosen for comparison. The relationships between visual atmosphere and percentages for the musical evaluations (no effect/stimulating/distracting) and the average scores for the musical evaluations are shown in Figure 4A. The percentage who evaluated the music as stimulating was higher in the warm-toned space $(71 \%)$ than in the cold-toned space (58\%), and the converse applied to the proportion who evaluated the music as distracting. Average scores for musical evaluation were much higher in the warm-toned space $(M=3.16, S D=2.214)$ than in the cold-toned space $(M=1.51, S D=3.894)$. The results of the $t$-test showed that there was a significant effect of visual atmosphere on musical evaluation $(t=-2.534, d f=108, p<0.05$, $d=0.50)$.
The average $d$-values for PAD emotional evaluations in spaces with different visual atmospheres are shown in Figure 4B. Pleasure, arousal, and dominance all increased to varying degrees. The $d$-values for arousal and dominance were $0.13-0.20$ higher in the cold-toned space than in the warm-toned space, while the $d$-value of pleasure in the warm-toned space $(M=0.72$, $S D=1.278)$ was higher than in the cold-toned space $(M=0.31$, $S D=2.284)$. The results of the $t$-test showed that visual atmosphere did not have a significant effect on pleasure $(d f=108, t=-1.066$, $p=0.289, d=0.21)$, arousal $(d f=108, t=0.285, p=0.776, d=0.06)$, or dominance $(d f=108, t=0.508, p=0.613, d=0.10)$.

\section{Sound Atmosphere}

In accordance with subjective evaluation of background sound under the uncontrolled condition, the experimental sites were sorted into quiet spaces and noisy spaces. FFR and CS (which had the same spatial function but a clear difference in sound atmosphere evaluation) were chosen for comparison. The relationships between sound atmosphere and percentages for musical evaluations (no effect/stimulating/distracting) and average scores for musical evaluations are shown in Figure 5A. The percentage of evaluations that rated the music as having a stimulating effect was much higher in the quiet space $(50 \%)$ than in the noisy space (26\%). The proportion of evaluations that rated the music as having no effect on communication was similar in two spaces (ranging from 7 to $11 \%$ ). It was noticeable that a substantial proportion of communicators (63\%) in noisy spaces thought that the music had no effect on communication. Average scores for musical evaluation were higher in the quiet space $(M=1.91, S D=2.896)$ than in the noisy space $(M=0.82, S D=3.402)$. The results of the $t$-test showed that there was no significant effect of sound atmosphere on musical evaluation $(t=-1.801, d f=109, \quad p=0.074<0.1$, $d=0.34)$.

The average $d$-values for PAD emotional evaluations in spaces with different sound atmospheres are shown in Figure 5B. The $d$-values for pleasure, arousal, and dominance increased by $0.26(S D=2.130), 1.07(S D=1.725)$, and $0.78(S D=1.910)$ in quiet spaces, but decreased by $0.72 \quad(S D=2.085), 0.04$ $(S D=1.870)$, and $0.23(S D=1.536)$ in noisy spaces. The results of the $t$-test showed that there was a significant effect of music on pleasure $(t=2.446, d f=109, p<0.05, d=0.46)$, arousal $(t=3.243$, $d f=109, p<0.01, d=0.62)$, and dominance $(t=3.066, d f=109$, 


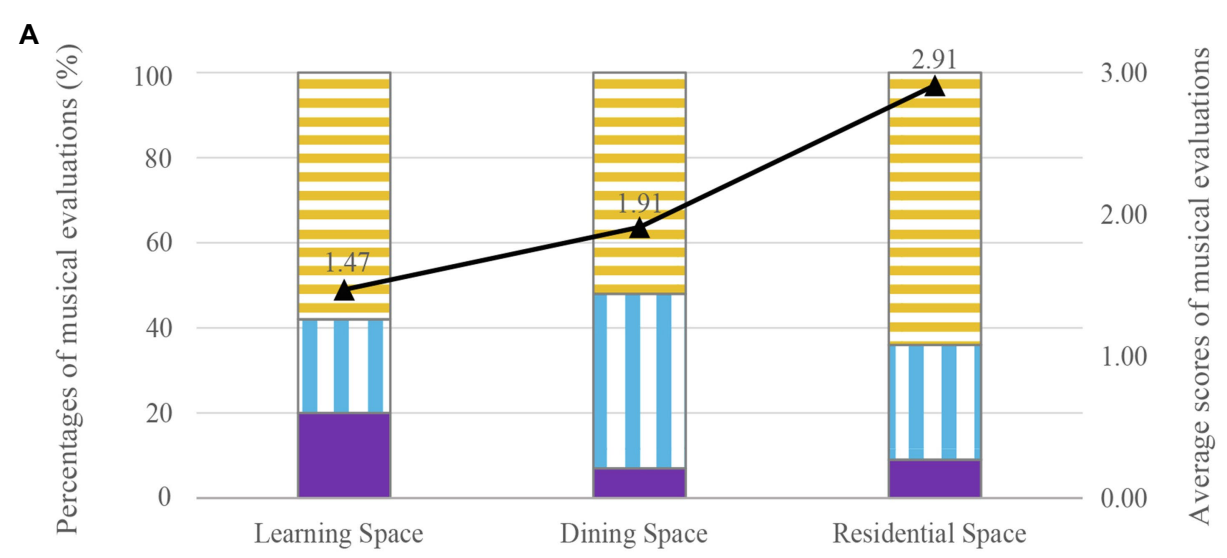

Distractive $\square \square$ No Effect $\square$ Stimulating $\longrightarrow$ Overall Evaluation Scores

B

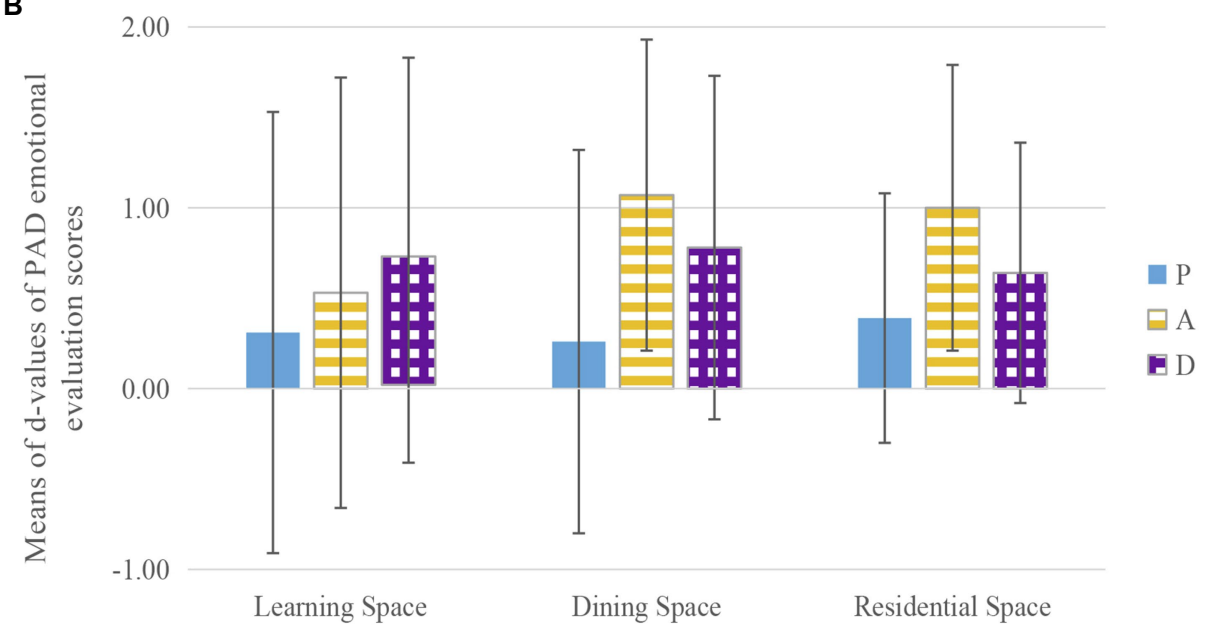

FIGURE 3 | The effects of music on communication in spaces with different functions: (A) the effects of music on musical evaluation, (B) the effects of music on pleasure-arousal-dominance (PAD) emotional evaluation.

$p<0.01, d=0.58)$ in spaces with different sound atmospheres. These findings indicate that music can be effective in enhancing pleasure, arousal, and dominance during communication in quiet spaces.

\section{Interior Furnishings}

Diversity of furniture is one of the main factors to evaluate the interior furnishings (Kaye and Murray, 1982). In this study, the experimental sites were sorted into minimal spaces (within three) and abundant spaces (more than three) in terms of the number of furniture types. DT and LR which had the same spatial function and visual and sound atmospheres but a clear difference in interior furnishings were chosen for comparison. The relationships between interior furnishings and the percentages for musical evaluations (no effect/stimulating/ distracting) and the average scores for musical evaluations are shown in Figure 6A. The proportion of evaluations that rated the music as stimulating and as distracting were similar in the two groups (from 50 to $59 \%$ and from 9 to $13 \%$, respectively). The percentage of evaluations that rated the music as having no effect was higher in the abundant space $(41 \%)$ than in the minimal space (28\%). Average scores for musical evaluation were slightly higher in the abundant space $(M=2.81, S D=3.693)$ than in the minimal space $(M=2.59, S D=3.853)$. The results of the $t$-test showed that there was no significant effect of interior furnishings on musical evaluation $(t=-0.279, d f=108$, $p=0.781, d=0.06$ ).

The average $d$-values for PAD emotional evaluations in spaces with different interior furnishings are shown in Figure 6B. The $d$-values for pleasure and arousal were similar in the minimal space and abundant spaces, increasing by 0.40 $(S D=1.515), 0.44 \quad(S D=1.703), 0.86 \quad(S D=1.673)$, and 0.81 $(S D=2.086)$, respectively. The $d$-value for dominance was higher in the minimal space $(M=0.76, S D=1.379)$ than in abundant spaces $(M=0.13, S D=1.185)$. The results of the $t$-test showed that there was a significant effect of music on dominance in spaces with different interior furnishings $(t=2.268, d f=108$, 


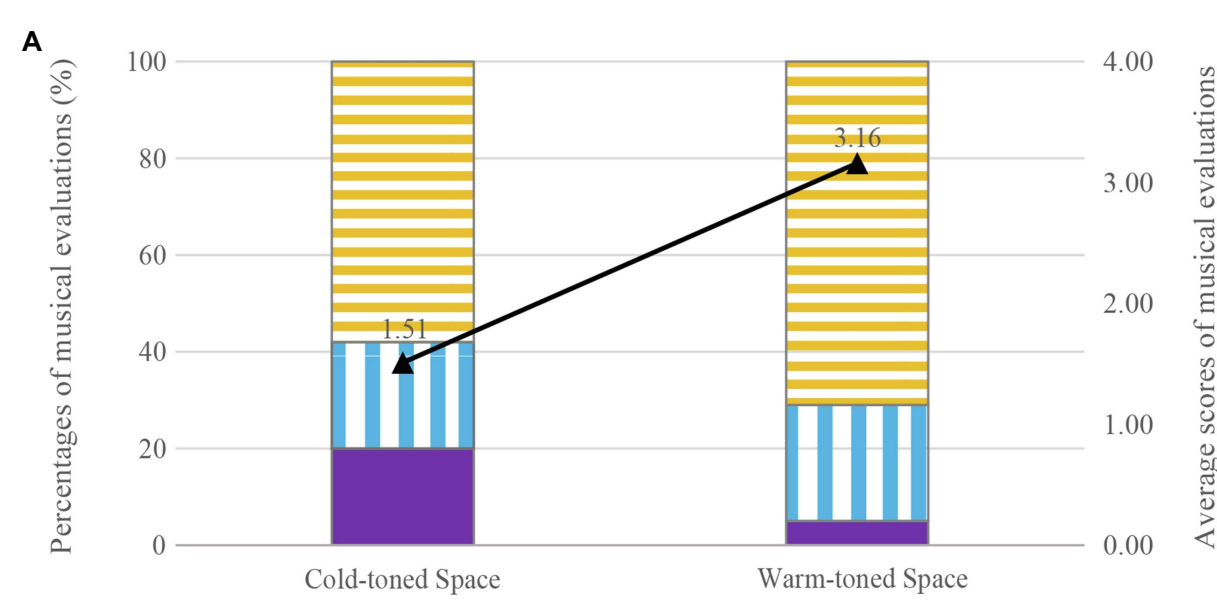

$\square$ Distractive $\square$ No Effect $\square$ Stimulating $\longrightarrow$ Overall Evaluation Scores

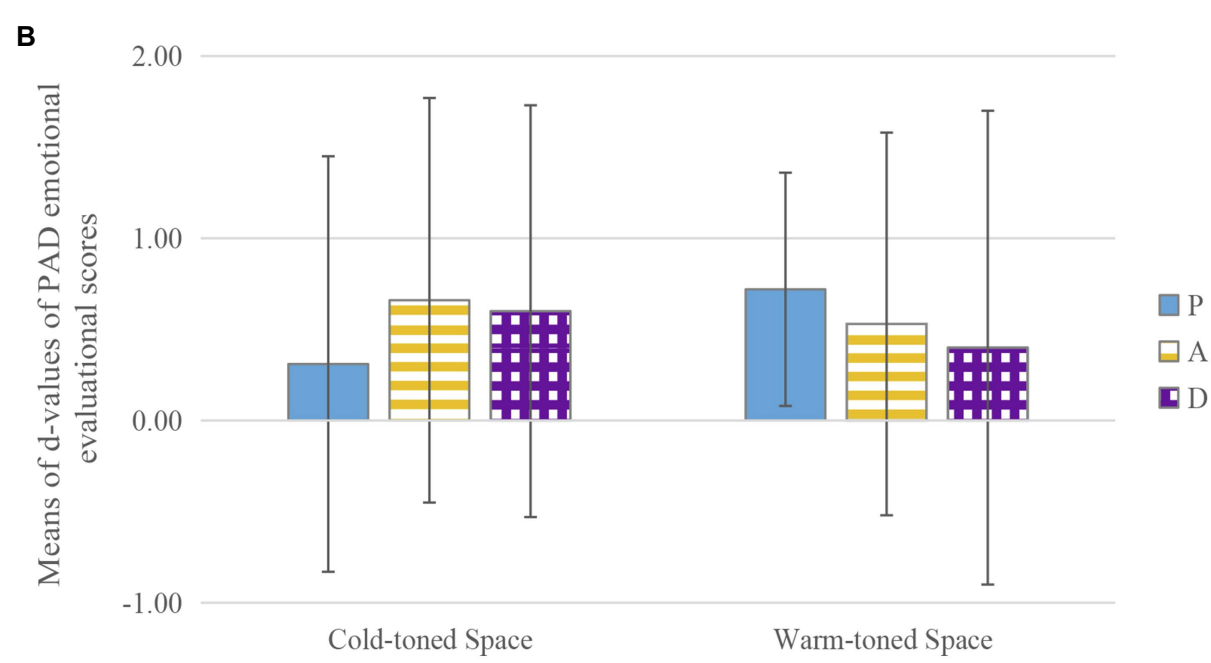

FIGURE 4 | The effects of music on communication in spaces with different visual atmospheres: (A) the effects of music on musical evaluation, (B) the effects of music on PAD emotional evaluation

$p<0.05, d=0.48)$. This finding indicates that the positive effect of music on dominance during communication was significant in the minimal space.

\section{Social Characteristics}

Studies have found that social characteristics such as gender, age, and situation can lead to different emotion evaluations (Gabrielsson, 2002; Hunter et al., 2011; Schubert, 2013). In accordance with the behavioral mode of communication, this study analyzed the effects of music on participants with different intimacy levels, in different gender combinations and in groups of different sizes during communication. Based on the number of treatments, ANOVA was used to test for significant differences in the various intimacy levels (stranger, acquaintance, and close friend) of participants (Starzyk et al., 2006). Independent $t$-tests were performed to assess differences between different gender combinations and number of participants. The average scores of musical evaluation and the $d$-values of PAD emotional evaluation were summarized, and the SD was identified via $t$-tests. The results are shown in Table 4.

The effects of music on communication varied in different functional indoor spaces when participants were with different social characteristics, such as intimacy level, gender combination, and group size of communicators.

In the learning space, there was a significant effect of music on dominance during communication in different gender combinations. The results of the $t$-tests showed that in comparison to mixed-gender groups $(M=-0.02, S D=1.737)$, dominance $(t=3.347, d f=108, p<0.01, d=0.64)$ was enhanced by music in single-gender groups $(M=1.23, S D=2.179)$.

In the dining space, compared to the intimacy levels of acquaintances and close friends, the average scores for musical 


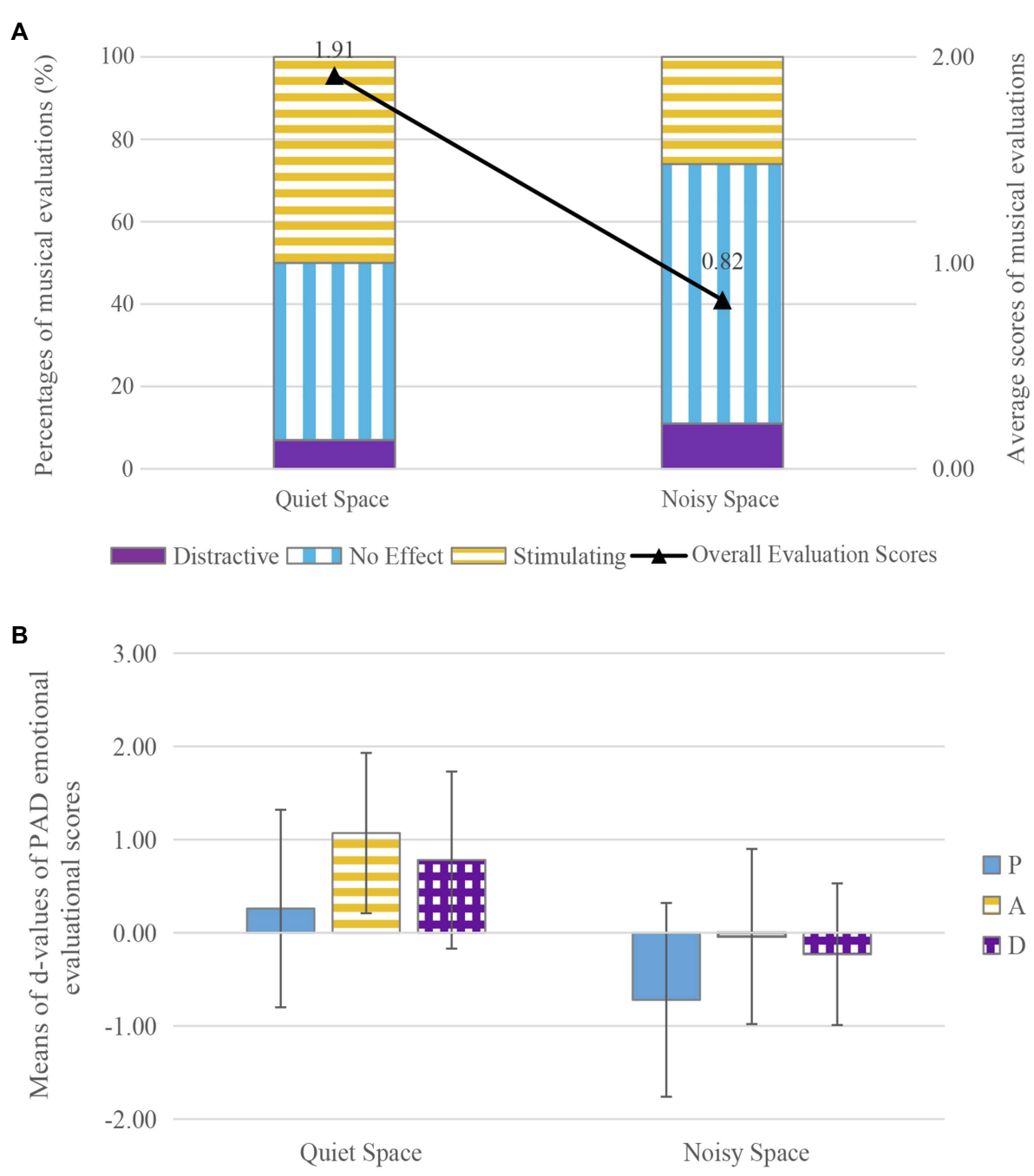

FIGURE 5 | The effects of music on communication in spaces with different sound atmospheres: (A) the effects of music on musical evaluation, (B) the effects of music on PAD emotional evaluation.

evaluation were 1.54-2.03 higher in the group of strangers. The results of the ANOVA indicated that communication was promoted to some extent when participants were strangers $(d f 1=2, d f 2=108, F=2.639, p=0.076<0.1, d=0.28)$, meanwhile, $d$-values of pleasure $(d f 1=2, d f 2=108, F=2.541, p=0.083<0.1$, $d=0.48)$ and arousal $(d f 1=2, d f 2=108, F=2.369, p=0.098<0.1$, $d=0.49$ ) were higher in the stranger group. Further, all of the musical evaluation scores and $d$-values for emotional evaluations were higher when there were more than two participants, and the results of the $t$-tests show that there was an significant effect of music on pleasure $(t=-2.008, d f=109, p<0.05, d=0.38)$ and arousal $(t=-2.412, d f=109, p<0.05, d=0.46)$.

In the residential space, the average scores for musical evaluation were 2.66 higher in acquaintances compared to close friends. The results of the $t$-tests show that there was a significant effect of music on communication $(t=3.448$, $d f=108, p<0.01, d=0.72)$, and pleasure $(t=-2.008, d f=108$, $p<0.05, d=0.52)$ and dominance $(t=-2.412, d f=108, p<0.01$, $d=0.67$ ) were efficiently enhanced by music in the group of acquaintances.

Therefore, in terms of social characteristics, there is evidence that when in the learning space, using music to promote communication is more suitable for single-gender groups. And when there are more than two communicators in the dining space, pleasure and arousal can be efficiently enhanced by music. In the residential space, when the intimacy level of roommates is not that close, music environment can be an effective way to promote communication.

\section{DISCUSSION}

This paper contributes to the body of research into the effects of audiovisual interaction on social interaction by comparing the effects of music on communication in different spaces in terms of function, visual atmosphere, sound atmosphere, and 


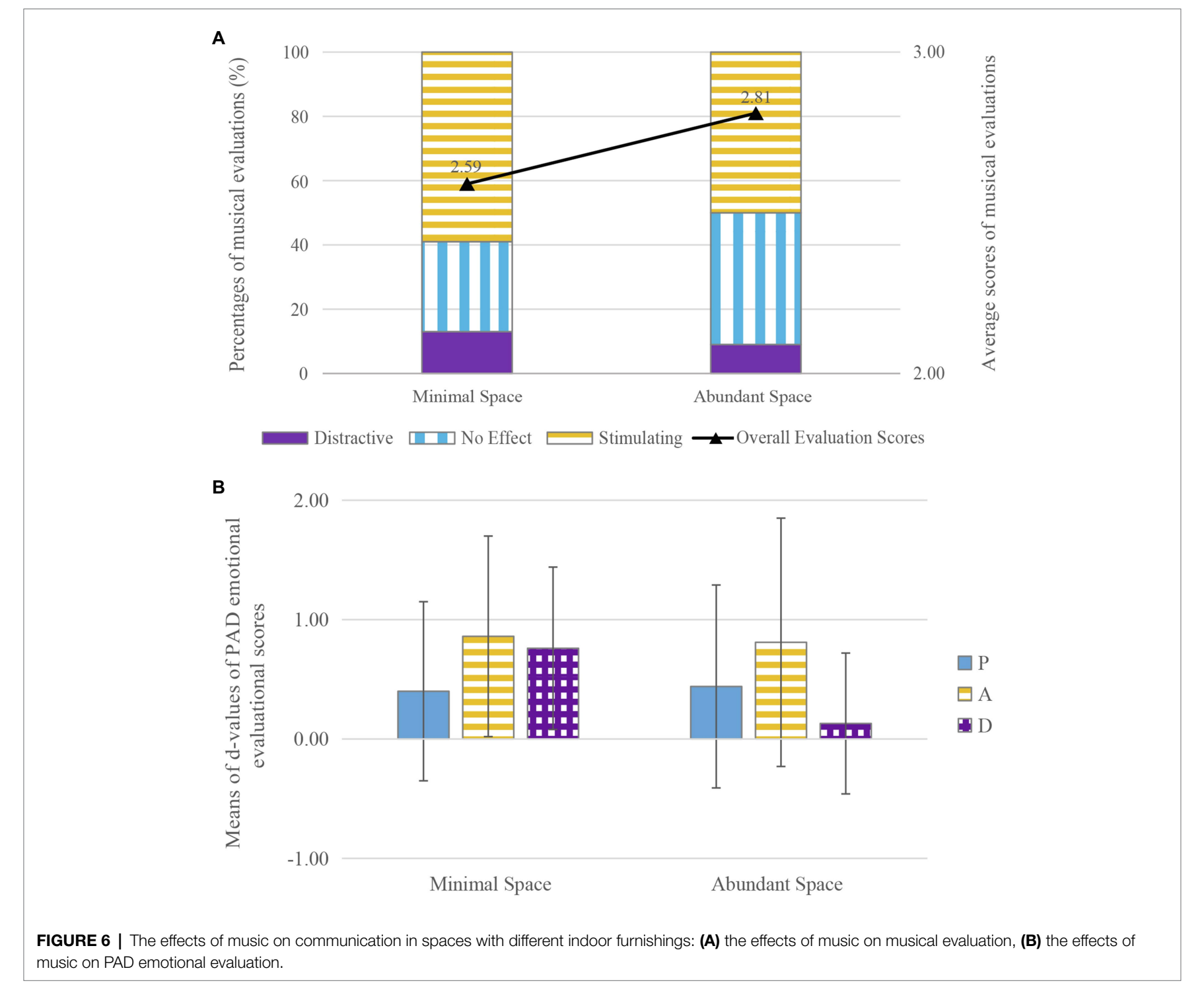

interior furnishings. In terms of spatial function, people have particular behavioral patterns in specific functional spaces (for instance, eating meals in a restaurant, or resting in a bedroom). In this study, spaces for learning, dining, and resting were chosen in accordance with the main activities of college students.

The results were inconsistent with Hypothesis 1; there were no significant differences between the effects of music on communication or emotion during communication in spaces with different functions. Post-experiment interview suggested that this result is to some extent attributable to the fact that chatting is a common behavior pattern in all the spaces, regardless of their primary function, and thus all the sites were suitable for communication. Compared to spatial function, the degree of privacy offered by a space may have a more significant effect on communication. Numerous studies have explored the need for privacy and intelligibility of speech in different spaces, such as open-plan offices, hospitals, and residences (Cavanaugh and Hirtle, 2006; Virjonen et al., 2007;
Roy, 2017), finding that people's satisfaction is closely related to speech privacy. To date, most studies have focused on the analysis of emotional feelings in specific spaces, with little horizontal comparison across different functional spaces. Thus, the results of this part of the present study provide a point of reference for future research.

For Hypothesis 2 on visual atmosphere, the results show that music had greater effects on communication in the warmtoned spaces than in the cold-toned spaces. However, there were no significant differences in the effects of music on pleasure, arousal, or dominance in spaces with different visual atmospheres. The effect size of the PAD emotional evaluations did not seem to match the overall effects of music on communication. Previous studies indicate that experiences of color have their roots in conscious, subconscious, and unconscious processes of human behaviors (Reddy et al., 2012) and that the effect of music on emotional intervention plays a dominant role, followed by color (Li et al., 2018). 
TABLE 4 | Musical and emotional evaluations in terms of social characteristics.

$\vec{\omega}$

\begin{tabular}{|c|c|c|c|c|c|c|c|}
\hline \multirow{2}{*}{ Site } & \multirow{2}{*}{ Statistical test } & \multirow{2}{*}{\multicolumn{2}{|c|}{ Social characteristic }} & \multirow{2}{*}{ Musical evaluation } & \multicolumn{3}{|c|}{ D-values for emotional evaluation } \\
\hline & & & & & Pleasure & Arousal & Dominance \\
\hline \multirow{7}{*}{ Learning space } & \multirow{3}{*}{ ANOVA } & \multirow{3}{*}{ Intimacy level } & Stranger & 2.03 & 0.93 & 0.67 & 0.60 \\
\hline & & & Acquaintance & 2.06 & 0.66 & 0.28 & 0.72 \\
\hline & & & Close friend & 2.29 & 0.06 & 0.79 & 0.33 \\
\hline & \multirow{4}{*}{$t$-test } & \multirow{2}{*}{ Gender combination } & Single gender & $1.83(\mathrm{SD}=3.679)$ & $0.57(\mathrm{SD}=1.839)$ & $0.53(\mathrm{SD}=2.052)$ & $1.23(\mathrm{SD}=2.179)$ \\
\hline & & & Mixed gender & $2.40(\mathrm{SD}=3.231)$ & $0.40(\mathrm{SD}=2.052)$ & $0.67(\mathrm{SD}=2.155)$ & $-0.02(S D=1.737)$ \\
\hline & & \multirow{3}{*}{ Group size } & One-on-one & $2.13(\mathrm{SD}=3.553)$ & $0.34(\mathrm{SD}=1.873)$ & $0.53(\mathrm{SD}=2.276)$ & $0.49(\mathrm{SD}=2.062)$ \\
\hline & & & Multi participants & $2.26(\mathrm{SD}=2.958)$ & $0.96(\mathrm{SD}=2.225)$ & $0.91(\mathrm{SD}=1.756)$ & $0.61(S D=1.924)$ \\
\hline \multirow{7}{*}{ Dining space } & \multirow{3}{*}{ ANOVA } & & Stranger & 2.71 & 0.29 & 0.81 & 0.86 \\
\hline & & \multirow[t]{2}{*}{ Intimacy level } & Acquaintance & 0.68 & -1.04 & -0.20 & 0.08 \\
\hline & & & Close friend & 1.17 & -0.11 & 0.68 & 0.14 \\
\hline & \multirow{4}{*}{$t$-test } & \multirow{2}{*}{ Gender combination } & Single gender & $1.02(\mathrm{SD}=3.514)$ & $-0.09(\mathrm{SD}=2.003)$ & $0.45(S D=1.768)$ & $0.13(\mathrm{SD}=1.585)$ \\
\hline & & & Mixed gender & $1.69(\mathrm{SD}=2.834)$ & $-0.40(\mathrm{SD}=2.306)$ & $0.56(\mathrm{SD}=1.998)$ & $0.40(\mathrm{SD}=1.987)$ \\
\hline & & \multirow{2}{*}{ Group size } & One-on-one & $1.22(\mathrm{SD}=3.037)$ & $-0.62(\mathrm{SD}=1.941)$ & $0.12(S D=1.767)$ & $0.02(\mathrm{SD}=1.600)$ \\
\hline & & & Multi participants & $1.51(\mathrm{SD}=3.402)$ & $0.20(S D=2.324)$ & $0.96(S D=1.918)$ & $0.55(\mathrm{SD}=1.973)$ \\
\hline \multirow{6}{*}{ Residential space } & \multirow{6}{*}{$t$-test } & \multirow{2}{*}{ Intimacy level } & Acquaintance & $3.97(\mathrm{SD}=3.551)$ & $0.97(\mathrm{SD}=1.204)$ & $1.00(\mathrm{SD}=1.901)$ & $1.22(\mathrm{SD}=1.237)$ \\
\hline & & & Close friend & $1.31(\mathrm{SD}=3.725)$ & $0.18(\mathrm{SD}=1.642)$ & $0.78(\mathrm{SD}=1.755)$ & $0.37(\mathrm{SD}=1.270)$ \\
\hline & & \multirow{2}{*}{ Gender combination } & Single gender & $2.08(\mathrm{SD}=3.908)$ & $0.44(\mathrm{SD}=1.609)$ & $0.92(\mathrm{SD}=1.837)$ & $0.60(\mathrm{SD}=1.357)$ \\
\hline & & & Mixed gender & $2.11(\mathrm{SD}=3.408)$ & $0.11(S D=0.928)$ & $0.00(\mathrm{SD}=0.866)$ & $0.78(S D=0.667)$ \\
\hline & & \multirow{2}{*}{ Group size } & One-on-one & $1.32(\mathrm{SD}=3.913)$ & $0.88(\mathrm{SD}=1.509)$ & $1.28(\mathrm{SD}=1.768)$ & $0.68(\mathrm{SD}=1.435)$ \\
\hline & & & Multi participants & $2.31(\mathrm{SD}=3.833)$ & $0.27(\mathrm{SD}=1.561)$ & $0.72(\mathrm{SD}=1.790)$ & $0.60(\mathrm{SD}=1.284)$ \\
\hline
\end{tabular}

D-values for emotional evaluation 
The present results may be due to the fact that music has a greater effect on emotion than color does. Against a given musical background, it may be difficult for participants to distinguish differences in the emotion during communication in spaces with different visual atmospheres, and it is likely that the complex influence mechanism of color on emotion cannot be expressed simply in terms of a three-dimensional emotion model.

In terms of sound atmosphere, the subject of Hypothesis 3 , the results indicate that communication can be enhanced by music in the quiet space to some degree, although, most of the communicators thought that there was almost no effect of music on communication in the noisy space. In the presence of music during communication, pleasure, arousal, and dominance all increased in the quiet space but decreased in the noisy space. These results are in line with previous research, which found that music plus ambient noise at comfortable levels of volume increases dining pleasure, while no music or a sound environment with music that is too loud has negative effects (Novak et al., 2010). It is worth noting that noise has both negative and positive aspects, and the absence of negative sound does not necessarily create a positive environment (Iyendo, 2016). Torresin et al. (2019) conducted a systematic review of positive indoor soundscapes; among their findings, specific sound types (i.e., natural sounds and sounds from residential areas) were found to reduce annoyance caused by disturbing tonal noises. Likewise, research exploring the acoustic environment of nursing homes showed that an environment that is rich and varied in sound sources tends to perform better in terms of safety and intimacy, as well as appropriateness, compared to monotonous and uneventful soundscapes (Aletta et al., 2017). Furthermore, the results of previous research have shown that musical evaluation during communication decreases sharply (from 1.31 to -2.13 ) when SPL exceeds $50 \mathrm{dBA}$, becoming negative when SPL reaches $60 \mathrm{dBA}$ (Meng et al., 2020). Therefore, neither playing music at an appropriate volume in a noisy space nor playing it at over $60 \mathrm{dBA}$ in a quiet space is likely to improve the quality of communication.

For the evaluations in regarding minimal and abundant interior furnishings, the subject of Hypothesis 4, the results indicate that there were no significant differences between the effects of music on communication in spaces that had been furnished differently, but that music can enhance dominance during communication in the minimally furnished space. This finding may be due to the fact that complicated furnishings can distract people's attention. A related study of the effects of commercial spatial factors on shopping behavior drew a similar conclusion; a complex grocery store environment was associated with low levels of pleasantness, delays in purchasing or even departures, as high levels of complexity can produce avoidance behaviors (Gilboa and Rafaeli, 2003). Differences in the arrangement as well as the density of furniture have been studied, showing that manipulation of furniture density may nullify the effects of arrangement; that is, with increasing density there is a corresponding decrease in distance between chairs, which is associated, up to a point, with increasing intimacy and friendliness (Kaye and Murray, 1982).

Communicators in the same seats had different spatial perceptions of scale that bore no clear relation to the indoor area. Take, for example, the learning corridor, which $53 \%$ of participants thought of as a large-scale space, whereas $47 \%$ held the opposite view. According to post-experiment interviews, the ratio of the length and width of a space, the density of crowds and furniture, and the enclosure mode of a space all affect the perception of spatial scale.

For Hypothesis 5, which focused on social characteristics, the results indicate that music had a different effect on communication when participants diverged in their intimacy levels, gender combinations and group size in different indoor spaces. In terms of intimacy level, the results showed the potential of music to strengthen social bonds in residential spaces. Compared to close friends, there was significant effect of music on acquaintances during communication, pleasure and dominance were effectively enhanced by music. Consistent with Hypothesis 5, Bronwyn et al. (2014) revealed the mechanism by which music enhances social bonds, indicating that listening to music facilitates endorphin release, which plays a central role in the maintenance of non-sexual, non-kinship social bonds. In this vein, roommate conflict is a key social problem in college (Sillars, 1980), and effective communication can enhance relationships among roommates (Wang et al., 2012). Music can thus be seen as an effective way to ease dormitory conflict when roommates have a low intimacy level.

In terms of gender combination, the results indicate that dominance during communication was significantly enhanced by music for single-gender groups in the learning spaces. Numerous studies have explored the effects of gender composition on social interactions such as cooperation, group discussion, and group learning among children (Smith-Lovin, 1989; Ausch, 1994; Willoughby et al., 2009). For example, with respect to group learning, more collaborative behaviors have been found in mixedgender than in single-gender groups (Willoughby et al., 2009). Considering these findings in combination of the $d$-values of dominance in the learning spaces shown in Table 4, music can be considered an effective strategy to enhance dominance within single-gender groups, and to reduce differences in groups with gender combinations, during communication.

In terms of group size, the results show that music had greater effects on pleasure and arousal during communication when there were more than two participants in the dining spaces. A study of the effects of dining style on communication in restaurants indicated that when there were four or more diners per table, conversation increased compared to when there were fewer people, and frequency of conversation in centralized style (diners sharing a dish, such as a hot pot) was higher than in the separate (diners do not share dishes with others but eat their own food) with background music (Meng et al., 2017). Therefore, further confirmation of the most appropriate group size for communication in dining spaces is needed; in addition, dining style should be considered. 


\section{SUMMARY AND CONCLUSION}

Under the comprehensive pressures of academic and daily life, social anxiety is a widespread problem among college students, a particularly vulnerable group. Reliance on the Internet is an important factor in mental health, and the identification of ways to ease social barriers and to promote face-to-face communication is an important area of research. Using objective measurements of the natural sound environment and a subjective questionnaire survey of musical evaluations and PAD emotional evaluations during communication, this study examined the influence of music on emotion during communication in different indoor spaces and reached a number of conclusions. First, there were no significant differences in musical or emotional evaluation during communication in different functional spaces. Second, the positive effects of music were higher in warmtoned spaces, whereas the differences in the effects of music on emotion during communication in spaces with different visual atmospheres were not significant. Third, music had a significant effect on both musical evaluation and emotion during communication in spaces with different sound atmospheres, indicating that it can promote communication in quiet spaces. Fourth, in terms of interior furnishings, music in simply furnished spaces can enhance dominance. The effects of music on dominance were also higher in single-gender groups than in mixed-gender groups.

\section{LIMITATIONS}

The present study can help improve communication by regulating spatial factors with music in terms of visual atmosphere, sound atmosphere, and interior furnishings. However, the study has a number of limitations which indicate that certain questions need to be discussed further.

There are rich varieties of musical emotions, and musical emotion characteristics can be classified based on musical dimensions such as pitch height, loudness, timbre, tempo, and intensity (Wieczorkowska et al., 2006). For example, Hevner (1936) presented eight synonym clusters to describe emotional perceptions of music, including happiness, gracefulness, sereneness, dreaminess, sadness, dignity, vigorousness, and excitement. The level of emotional perception of music varies with regard to different musical emotions (Baumgartner et al., 2006), and the emotion evoked by music is not always consistent with the perceived emotion (Gabrielsson, 2002). However, only one excerpt of peaceful music was used in the given experimental settings, and future research should seek to combine a wider range of music with different types of spaces.

In terms of the selection of experimental sites, limitations in terms of being able to control variables when comparing two spaces might have caused the results to be confounded by uncontrolled factors. In addition to the variables listed in this research, the spatial scale, dynamism, and indoor partitions are key factors of spatial perceptions and thus impact emotions (Hogg et al., 2011; Maheshwari et al., 2019). For instance, small rooms are considered more pleasant, calmer, and safer than large rooms (Tajadura-Jiménez et al., 2010). Regarding the visual atmosphere, the colors of the spaces were simply divided into warm-toned and cold-toned, while color harmony, as well as saturation and brightness, of color also impact emotion (Shen et al., 2015). In order to minimize the effects of uncontrolled spatial factors, virtual reality (VR) technology that provides a realistic and immersive environment (Chamilothori et al., 2019) can be considered for use in further studies.

Emotions are internal and mostly conscious, and self-report is an accepted way to evaluate them (Bradley and Lang, 1994). However, individuals have no direct access to the causal connections between external forces and internal responses - they are simply limited in their ability to track the complex causal story of their emotions (Russell, 2003). In addition, self-reports frequently refer to a certain period experienced in the past, and usually only salient single moments of the episode overall are emphasized (Fredrickson and Kahneman, 1993; Fiebig et al., 2020); thus, retrospective biases also need to be taken into account (Robinson and Clore, 2002). As the results of this study are based on self-reports, future studies should collect data regarding physiological changes to support the above findings.

\section{DATA AVAILABILITY STATEMENT}

The raw data supporting the conclusions of this article will be made available from the corresponding author upon reasonable request.

\section{ETHICS STATEMENT}

The studies involving human participants were reviewed and approved by ethics committee, School of Architecture, Harbin Institute of Technology. Written informed consent for participation was not required for this study in accordance with the national legislation and the institutional requirements.

\section{AUTHOR CONTRIBUTIONS}

JJiang participated in the investigation, data curation, and writing of the original draft. QM provided conceptualization and participated in writing and editing the manuscript and in funding acquisition. JJi participated in the methodology, validation, and formal analysis. All authors contributed to the article and approved the submitted version.

\section{FUNDING}

This research was funded by the National Natural Science Foundation of China (NSFC), grant numbers 51878210, 51678180, and 51608147, the Natural Science Foundation of Heilongjiang Province, grant number YQ2019E022 and the Open Projects Fund of Key Laboratory of Ecology and Energy-saving Study of Dense Habitat (Tongji University), Ministry of Education (2020030103). 


\section{ACKNOWLEDGMENTS}

This research was conducted based on previously published papers entitled The Influence of Background Music on Interactive

\section{REFERENCES}

Aletta, F., Botteldooren, D., Thomas, P., Mynsbrugge, T. V., Vriendt, P. D., Velde, D. V. D., et al. (2017). Monitoring sound levels and soundscape quality in the living rooms of nursing homes: a case study in flanders (Belgium). Appl. Sci. 7:874. doi: 10.3390/app7090874

Altomonte, S. (2017). Indoor environmental quality: lighting and acoustics. Encycl. Sustainable Technol. 2, 221-229. doi: 10.1016/B978-0-12-409548-9. 10196-4

Andreassen, C. S., and Pallesen, S. (2014). Social network site addiction-an overview. Curr. Pharm. Des. 20, 4053-4061. doi: 10.2174/13816128113199990616

Ausch, L. (1994). Gender comparisons of young children's social interaction in cooperative play activity. Sex Roles 31, 225-239. doi: 10.1007/BF01547716

Baumgartner, T., Esslen, M., and Jäncke, L. (2006). From emotion perception to emotion experience: emotions evoked by pictures and classical music. Int. J. Psychophysiol. 60, 34-43. doi: 10.1016/j.ijpsycho.2005.04.007

Blouin, A. M., Fried, I., Wilson, C. L., Staba, R. J., Behnke, E. J., Lam, H. A., et al. (2013). Human hypocretin and melanin-concentrating hormone levels are linked to emotion and social interaction. Nat. Commun. 4:1547. doi: $10.1038 /$ ncomms 2461

Boer, M. J. D., Başkent, D., and Cornelissen, F. W. (2018). "Audio-visual interaction in emotion perception for communication: doctoral symposium, extended abstract." In Proceedings of the 2018 ACM Symposium on Eye Tracking Research and Applications; June 14-17, 2018.

Boukhechba, M., Chow, P., Fua, K., Teachman, B. A., and Barnes, L. E. (2018). Predicting Social Anxiety From Global Positioning System Traces of College Students: Feasibility Study. JMIR Mental Health 5:e10101. doi: 10.2196/10101

Bowers, A. R., MeeK, C., and Stewart, N. (2010). Illumination and Reading performance in age-related macular degeneration. Clin. Exp. Optom. 84, 139-147. doi: 10.1111/j.1444-0938.2001.tb04957.x

Bradley, M., and Lang, P. J. (1994). Measuring emotion: the self-assessment manikin and the semantic differential. J. Behav. Ther. Exp. Psychiatry 25, 49-59. doi: 10.1016/0005-7916(94)90063-9

Bronwyn, T., Launay, J., and Dunbar, R. I. M. (2014). Music and social bonding: "self-other" merging and neurohormonal mechanisms. Front. Psycho. 5:1096. doi: 10.3389/fpsyg.2014.01096

Brown, A. L., Kang, J., and Gjestland, T. (2011). Towards standardization in soundscape preference assessment. Appl. Acoust. 72, 387-392. doi: 10.1016/j. apacoust.2011.01.001

Carlucci, S., Causone, F., Rosa, F. D., and Pagliano, L. (2015). A review of indices for assessing visual comfort with a view to their use in optimization processes to support building integrated design. Renew. Sust. Energ. Rev. 47, 1016-1033. doi: 10.1016/j.rser.2015.03.062

Cavanaugh, W., and Hirtle, P. (2006). Speech privacy in buildings: A review. J. Acoust. Soc. Am. 119:3325. doi: 10.1121/1.4786368

Chamilothori, K., Chinazzo, G., Rodrigues, J., Dan-Glauser, E., Wienold, J., and Andersen, M. (2019). Subjective and physiological responses to façade and sunlight pattern geometry in virtual reality. Build. Environ. 150, 144-155. doi: 10.1016/j.buildenv.2019.01.009

Chanda, M. L., and Levitin, D. J. (2013). The neurochemistry of music. Trends Cogn. Sci. 17, 179-193. doi: 10.1016/j.tics.2013.02.007

Côté, S. (2005). A social interaction model of the effects of emotion regulation on work strain. Acad. Manag. Rev. 30, 509-530. doi: 10.5465/amr.2005.17293692

Crandell, C. C., Smaldino, J. J., and Kreisman, B. M. (2004). Classroom acoustic measurements. Semin. Hear. 25, 189-200. doi: 10.1055/s-2004-828669

Dabbs, J. M., and Janis, I. L. (1965). Why does eating while reading facilitate opinion change?-An experimental inquiry. J. Exp. Soc. Psychol. 1, 133-144. doi: 10.1016/0022-1031(65)90041-7

Danielsson, C. B., Chungkham, H. S., Wulff, C., and Westerlund, H. (2014). Office design's impact on sick leave rates. Ergonomics 57, 139-147. doi: 10.1080/00140139.2013.871064
Behaviour in an Indoor Space and Effects of the Musical Sound Environment on Communicating Emotion. All authors thank the college students for their participation in this series of experiments.

Dong, P., and Wyer, R. S. (2014). How time flies: the effects of conversation characteristics and partner attractiveness on duration judgments in a social interaction. J. Exp. Soc. Psychol. 50, 1-14. doi: 10.1016/j.jesp.2013. 08.005

Evans, T. M., Bira, L., Gastelum, J. B., Weiss, L. T., and Vanderford, N. L. (2018). Evidence for a mental health crisis in graduate education. Nat. Biotechnol. 36, 282-284. doi: 10.1038/nbt.4089

Fiebig, A., Jordan, P., and Moshona, C. C. (2020). Assessments of acoustic environments by emotions - The application of emotion theory in soundscape. Front. Psychol. 11:573041. doi: 10.3389/fpsyg.2020.573041

Fredrickson, B. L., and Kahneman, D. (1993). Duration neglect in retrospective evaluations of affective episodes. J. Pers. Soc. Psychol. 65, 45-55. doi: 10.1037/ 0022-3514.65.1.45

Gabrielsson, A. (2002). Emotion perceived and emotion felt: same or different? Music. Sci. 5(suppl. 1), 123-147. doi: 10.1177/10298649020050S105

Gärling, T., Ettema, D., Connolly, F. F., Friman, M., and Olsson, L. E. (2020) Review and assessment of self-reports of travel-related emotional wellbeing. J. Transp. Health 17:100843. doi: 10.1016/j.jth.2020.100843

Gilboa, S., and Rafaeli, A. (2003). Store environment, emotions and approach behaviour: applying environmental aesthetics to retailing. Int. Rev. Retail Distrib. Consum. Res. 13, 195-211. doi: 10.1080/0959396032000069568

Goshvarpour, A., Abbasi, A., and Goshvarpour, A. (2017). An accurate emotion recognition system using ECG and GSR signals and matching pursuit method Biom. J. 40, 355-368. doi: 10.1016/j.bj.2017.11.001

Gudykunst, W. B., and Shapiro, R. B. (1996). Communication in everyday interpersonal and intergroup encounters. Int. J. Intercult. Relat. 20, 19-45. doi: 10.1016/0147-1767(96)00037-5

Gunes, H., and Pantic, M. (2010). Automatic, dimensional and continuous emotion recognition. Inter. J.Synthetic Emotions 1, 68-99. doi: 10.4018/ jse. 2010101605

Hans-Eckhardt, S. (2017). Music-evoked emotions-current studies. Front. Neurosci. 11:600. doi: 10.3389/fnins.2017.00600

Harrison, G. W. (2003). Field experiments and methodological intolerance. J. Econ. Methodol. 20, 103-117. doi: 10.1080/1350178X.2013.804678

Hatfield, E., Cacioppo, J. T., and Rapson, R. L. (1993). Emotional Contagion. Curr. Dir. Psychol. Sci. 2, 96-99. doi: 10.1111/1467-8721.ep10770953

Havlena, W. J., Holbrook, M. B., and Lehmann, D. R. (2010). Assessing the validity of emotional typologies. Psychol. Mark. 6, 97-112. doi: 10.1002/ mar.4220060203

Hess, U., and Blairy, S. (2001). Facial mimicry and emotional contagion to dynamic emotional facial expressions and their influence on decoding accuracy. Int. J. Psychophysiol. 40, 129-141. doi: 10.1016/S0167-8760(00) 00161-6

Hevner, K. (1936). Experimental studies of the elements of expression in music. Am. J. Psychol. 48, 246-268. doi: 10.2307/1415746

Hidayetoglu, M. L., Yildirim, K., and Akalin, A. (2012). The effects of color and light on indoor wayfinding and the evaluation of the perceived environment. J. Environ. Psychol. 32, 50-58. doi: 10.1016/j.jenvp.2011.09.001

Hogg, J., Goodman, S., Porter, T., Mikellides, B., and Preddy, D. E. (2011). Dimensions and determinants of judgements of colour samples and a simulated interior space by architects and non-architects. Br. J. Psychol. 70, 231-242. doi: 10.1111/j.2044-8295.1979.tb01680.x

Hunter, P. G., and Schellenberg, E. G. (2010). Music and emotion. Music Percept. 36, 129-164. doi: 10.1007/978-1-4419-6114-3_5

Hunter, P. G., Schellenberg, E. G., and Stalinski, S. M. (2011). Liking and identifying emotionally expressive music: age and gender differences. J. Exp. Child Psychol. 110, 80-93. doi: 10.1016/j.jecp.2011.04.001

Huron, D. (2011). Why is sad music pleasurable? A possible role for prolactin. Music. Sci. 15, 146-158. doi: 10.1177/1029864911401171

Iyendo, T. O. (2016). Exploring the effect of sound and music on health in hospital settings: A narrative review. Int. J. Nurs. Stud. 63, 82-100. doi: 10.1016/j.ijnurstu.2016.08.008 
Jensen, T. W., and Pedersen, S. B. (2016). Affect and affordances - The role of action and emotion in social interaction. Cognit. Semiotics 9, 79-103. doi: 10.1515/cogsem-2016-0003

Jiang, J., Meng, Q., and Kang, J. (2019). “The Influence of Background Music on Interactive Behaviour in an Indoor Space." In Proceedings of the 49th International Congress and Exposition on Noise Control Engineering (Internoise 2019); June 16-19 2019; Madrid, Spain.

Juslin, P. N., and Västfäll, D. (2008). Emotional responses to music: the need to consider underlying mechanisms. Behav. Brain Sci. 31:751. doi: 10.1017/ S0140525X08006079

Kaye, S. M., and Murray, M. A. (1982). Evaluations of an architectural space as a function of variations in furniture arrangement, furniture density, and windows. Human Factors Soci. 24, 609-618. doi: 10.1177/001872088202400511

Kim, D. H., and Mansfield, K. (2021). Creating positive atmosphere and emotion in an office-like environment: a methodology for the lit environment. Build. Environ. 194:107686. doi: 10.1016/j.buildenv.2021.107686

Koelsch, S. (2014). Brain correlates of music-evoked emotion. Nat. Rev. Neurosci. 15, 170-180. doi: $10.1038 / \mathrm{nrn} 3666$

Koelsch, S., and Skouras, S. (2014). Functional centrality of amygdala, striatum and hypothalamus in a small-world network underlying joy: An fMRI study with music. Hum. Brain Mapp. 35, 3485-3498. doi: 10.1002/hbm.22416

Koneni, V. J. (2008). Does music induce emotion? A theoretical and methodological analysis. Psychol. Aesthet. Creat. Arts 2:115. doi: 10.1037/1931-3896.2. 2.115

Krupa, M., Boominathan, P., Sebastian, S., and Ramanan, P. V. (2018). Assessment of communication in children With autism Spectrum disorder in South India: influence of environment. Commun. Disord. Q. 41, 34-41. doi: $10.1177 / 1525740118793978$

Lazarus, R. S. (2014). Emotion and adaptation. J. Nerv. Ment. Dis. 181:207. doi: 10.1097/00005053-199303000-00014

Li, X., Yang, L., Wang, H., Liu, B., Li, J., Li, Z., et al. (2018). Intervention effect of color and sound cross-modal correspondence between interaction of emotion and ambient. Commun. Comput. Infor. Sci. 851, 412-419. doi: 10.1007/978-3-319-92279-9_55

Li, H., Zhu, Y., Qin, O., and Cao, B. (2012). A study on the effects of thermal, luminous, and acoustic environments on indoor environmental comfort in offices. Build. Environ. 49, 304-309. doi: 10.1016/j.buildenv.2011.07.022

Lin, L., Sidani, J. E., Shensa, A., Radovic, A., Miller, E., Colditz, J. B., et al. (2016). ASSOCIATION BETWEEN SOCIAL MEDIA USE AND DEPRESSION AMONG U.S. YOUNG ADULTS. Depression Anxiety 33, 323-331. doi: $10.1002 /$ da. 22466

Ma, W., and Thompson, W. F. (2016). Human emotions track changes in the acoustic environment. Proc. Nat. Acad. Sci. U. S. A. 112, 14563-14568. doi: 10.1073/pnas.1515087112

Ma, K. W., Wong, H. M., and Mak, C. M. (2018). A systematic review of human perceptual dimensions of sound: meta-analysis of semantic differential method applications to indoor and outdoor sounds. Build. Environ. 133, 123-150. doi: 10.1016/j.buildenv.2018.02.021

Maheshwari, N., Srivastava, S., and Rajan, K. S. (2019). Development of an indoor space semantic model and its implementation as an indoorgml extension. Inter. J. Geo-Information 8:333. doi: 10.3390/ijgi8080333

Manav, B. (2017). Color-emotion associations, designing color schemes for urban environment-architectural settings. Color. Res. Appl. 42, 631-641. doi: $10.1002 / \mathrm{col} .22123$

Mehrabian, A. (1996). Pleasure-arousal-dominance: a general framework for describing and measuring individual differences in temperament. Curr. Psychol. 14, 261-292. doi: 10.1007/BF02686918

Mehrabian, A, and Russell, J. A. (1974). An Approach to Environmental Psychology. Cambridge, MA, USA: Massachusetts Institute of Technology

Meng, Q., Jiang, J., Liu, F., and Xu, X. (2020). Effects of the musical sound environment on communicating emotion. Int. J. Environ. Res. Public Health 17:2499. doi: 10.3390/ijerph17072499

Meng, Q., Zhang, S., and Kang, J. (2017). Effects of typical dining styles on conversation behaviours and acoustic perception in restaurants in China. Build. Environ. 121, 148-157. doi: 10.1016/j.buildenv.2017.05.025

Mirón, J., Goldberg, X., López-Solà, C., Nadal, R., Armario, A., Andero, R., et al. (2019). Perceived stress, anxiety and depression among undergraduate students: an online survey study. J. Depression Anxiety 8:1000330. doi: $10.4172 / 2167-1044.1000330$
Morgan, G. A., Gliner, J. A., and Harmon, R. J. (2000). Internal Validity. J. Amer. Acad. Child Adolescent Psychiat. 39, 529-531. doi: 10.1097/00004583200004000-00024

Nematchoua, M. K., Ricciardi, P., Orosa, J. A., Asadi, S., and Choudhary, R. (2019). Influence of indoor environmental quality on the self-estimated performance of office workers in the tropical wet and hot climate of Cameroon. J. Building Engineering 21, 141-148. doi: 10.1016/j.jobe.2018.10.007

Nicolaou, N., Malik, A., Daly, I., Weaver, J., Hwang, F., Kirke, A., et al. (2017). Directed motor-auditory EEG connectivity is modulated by music tempo. Front. Hum. Neurosci. 11:502. doi: 10.3389/fnhum.2017.00502

Niemelä, R., Hannula, M., Rautio, S., Reijula, K., and Railio, J. (2002). The effect of air temperature on labour productivity in call centres-a case study. Energy Buildings 34, 759-764. doi: 10.1016/S0378-7788(02) 00094-4

Novak, C. C., Lopa, J. L., and Novak, R. E. (2010). Effects of sound pressure levels and sensitivity to noise on mood and behavioral intent in a controlled fine dining restaurant environment. Culinary Sci. Technology 8, 191-218. doi: $10.1080 / 15428052.2010 .535756$

Olguin, D. O., Waber, B. N., Kim, T., Mohan, A., Ara, K., and Pentland, A. (2009). Sensible organizations: technology and methodology for automatically measuring organizational behavior. IEEE Trans. Syst. Man Cybern. B Cybern. 39, 43-55. doi: 10.1109/TSMCB.2008.2006638

Olsen, K. N., Dean, R. T., Stevens, C. J., and Bailes, F. (2015). Both acoustic intensity and loudness contribute to time-series models of perceived affect in response to music. Psychomusicology 25, 124-137. doi: 10.1037/ pmu0000087

Ono, E., Nozawa, T., Ogata, T., Motohashi, M., Higo, N., Kobayashi, T., et al. (2012). "Fundamental deliberation on exploring mental health through social interaction pattern." In ICME International Conference on Complex Medical Engineering (CME);July 14 2012; Kobe, Japan; 321-326.

Paquette, S., Takerkart, S., Saget, S., Peretz, I., and Belin, P. (2018). Crossclassification of musical and vocal emotions in the auditory cortex: crossclassification of musical and vocal emotions. Ann. N. Y. Acad. Sci. 1423, 329-337. doi: $10.1111 /$ nyas. 13666

Passero, C. R. M., and Zannin, P. H. T. (2010). Statistical comparison of reverberation times measured by the integrated impulse response and interrupted noise methods, computationally simulated with ODEON software, and calculated by Sabine, Eyring and Arau-Puchades formulas. Appl. Acoust. 71, 1204-1210. doi: 10.1016/j.apacoust.2010.07.003

Patel, V., Flisher, A. J., Hetrick, S., and Mcgorry, P. (2007). Mental health of young people: A global public-health challenge. Lancet 369, 1302-1313. doi: 10.1016/s0140-6736 (07)60368-7

Petersen, S., and Knudsen, M. D. (2017). Method for including the economic value of indoor climate as design criterion in optimisation of office building design. Build. Environ. 122, 15-22. doi: 10.1016/j.buildenv.2017.05.036

Reddy, S. M., Chakrabarti, D., and Karmakar, S. (2012). Emotion and interior space design: an ergonomic perspective. Work 41, 1072-1078. doi: 10.3233/ WOR-2012-0284-1072

Robinson, M. D., and Clore, G. (2002). Episodic and semantic knowledge in emotional self-report: evidence for two judgment processes. J. Pers. Soc. Psychol. 83, 198-215. doi: 10.1037/0022-3514.83.1.198

Rosenthal, S. R., Zhou, J., and Booth, S. T. (2021). Association between mobile phone screen time and depressive symptoms among college students: A threshold effect. Human Behav. Emerging Technol. 3, 432-440. doi: $10.1002 / \mathrm{hbe} 2.256$

Roy, K. (2017). Possible path for speech privacy design and performance approaches. J. Acoustical Society America 142, 2626-2627. doi: 10.1121/ 1.5014619

Russell, J. A. (2003). Core affect and the psychological construction of emotion. Psychol. Rev. 110, 145-172. doi: 10.1037/0033-295X.110.1.145

Schubert, E. (2013). Emotion felt by the listener and expressed by the music: literature review and theoretical perspectives. Front. Psychol. 4:837. doi 10.3389/fpsyg.2013.00837

Shaver, P., Schwartz, J., Kirson, D., and O'Connor, C. (1987). Emotion knowledge: further exploration of a prototype approach. J. Pers. Soc. Psychol. 52, 1061-1086. doi: 10.1037/0022-3514.52.6.1061

Shen, Y., Yuan, W., Hsu, W., and Chen, Y. (2015). Color selection in the consideration of color harmony for interior design. Color. Res. Appl. 25, 20-31. doi: 10.1002/(SICI) 1520-6378(200002)25:1<20::AID-COL4>3.0.CO;2-5 
Sillars, A. L. (1980). Attributions and communication in roommate conflicts. Commun. Monogr. 47, 180-200. doi: 10.1080/03637758009376031

Smith-Lovin, L. (1989). Interruptions in group discussions: the effects of gender and group composition. Am. Sociol. Rev. 54, 424-435. doi: 10.2307/2095614

Starzyk, K. B., Holden, R. R., Fabrigar, L. R., and Macdonald, T. K. (2006). The personal acquaintance measure: a tool for appraising one's acquaintance with any person. J. Pers. Soc. Psychol. 90:833. doi: 10.1037/0022-3514.90. 5.833

Tajadura-Jiménez, A., Larsson, P., Väljamäe, A., Västfjäll, D., and Kleiner, M. (2010). When room size matters: acoustic influences on emotional responses to sounds. Emotion 10, 416-422. doi: 10.1037/a0018423

Thayer, R. E., and Mcnally, R. J. (1992). The Biopsychology of Mood and Arousal. Cogn. Behav. Neurol. 5, 65-74.

The 47th China Statistical Report on Internet Development (2021). Available at: http://www.cnnic.net.cn/hlwfzyj/hlwxzbg/ (Accessed February 3, 2021).

Torija, A. J., Ruiz, D. P., and Ramos-Ridao, A. F. (2012). Use of back-propagation neural networks to predict both level and temporal-spectral composition of sound pressure in urban sound environments. Build. Environ. 52, 45-56. doi: 10.1016/j.buildenv.2011.12.024

Torresin, S., Albatici, R., Aletta, F., Babich, F., and Kang, J. (2019). Assessment methods and factors determining positive indoor soundscapes in residential buildings: a systematic review. Sustain. For. 11:5290. doi: 10.3390/su11195290

Torresin, S., Albatici, R., Aletta, F., Babich, F., Oberman, T., Siboni, S., et al. (2020). Indoor soundscape assessment: a principal components model of acoustic perception in residential buildings. Build. Environ. 182:107152. doi: 10.1016/j.buildenv.2020.107152

Umberson, D., Anderson, K. L., Williams, K., and Chen, M. D. (2003). Relationship dynamics, emotion state, and domestic violence: a stress and masculinities perspective. J. Marriage Fam. 65, 233-247. doi: 10.1111/j.1741-3737. 2003.00233.x

Vasilski, D. (2016). On minimalism in architecture - space as experience. Spatium 1, 61-66. doi: 10.2298/SPAT1636061V

Virjonen, P., Keränen, J., Helenius, R., Hakala, J., and Hongisto, O. V. (2007). Speech privacy between neighboring workstations in an open office - a laboratory study. Acta Acust. united Acust. 93, 771-782. doi: 10.1134/ S1063771007050181

Wang, Q., Fink, E. L., and Cai, D. A. (2012). The effect of conflict goals on avoidance strategies: what does not communicating communicate? Hum. Commun. Res. 38, 222-252. doi: 10.1111/j.1468-2958.2011.01421.x

Weisburd, D. (2021). Talking to strangers: what we should know about the people we don't know. Cambridge J. Evidence-Based Policing 5, 67-79. doi: 10.1007/s41887-020-00058-9

Wieczorkowska, A., Synak, P., and Raś, Z. W. (2006). "Multi-label classification of emotions in music," in Intelligent Information Processing and Web Mining (Berlin, Heidelberg: Springer), 5, 307-315. doi: 10.1007/3-540-33521-8_30

Willoughby, T., Wood, E., Desjarlais, M., Williams, L., Leacy, K., and Sedore, L. (2009). Social interaction during computer-based activities: comparisons by number of sessions, gender, school-level, gender composition of the group, and computer-child ratio. Sex Roles 61, 864-878. doi: 10.1007/ s11199-009-9687-4

Wubben, M. J. J., Cremer, D. D., and Dijk, E. V. (2009). How emotion communication guides reciprocity: establishing cooperation through disappointment and anger. J. Exp. Soc. Psychol. 45, 987-990. doi: 10.1016/j. jesp.2009.04.010

Yamaguchi, T., Ota, J., and Otake, M. (2012). A system that assists group conversation of older adults by evaluating speech duration and facial expression of each participant during conversation. In Proceedings of the 2012 IEEE International Conference on Robotics and Automation; May 14-19, 2012; St Paul, MN, USA; 4481-4486.

Yang, Z., Asbury, K., and Griffiths, M. D. (2019). An exploration of problematic smartphone use among Chinese university students: associations with academic anxiety, academic procrastination, self-regulation and subjective wellbeing. Int. J. Ment. Heal. Addict. 17, 596-614. doi: 10.1007/s11469-018-9961-1

Yang, W., and Hodgson, M. (2006). Auralization study of optimum reverberation times for speech intelligibility for normal and hearing-impaired listeners in classrooms with diffuse sound fields. J. Acoust. Soc. Am. 120:801. doi: $10.1121 / 1.2216768$

Yang, W., and Moon, H. J. (2018). Combined effects of acoustic, thermal, and illumination conditions on the comfort of discrete senses and overall indoor environment. Build. Environ. 148, 623-633. doi: 10.1016/j.buildenv.2018. 11.040

Zhang, K., and Sun, S. (2013). Web music emotion recognition based on higher effective gene expression programming. Neurocomputing 105, 100-106. doi: 10.1016/j.neucom.2012.06.041

Zhang, S., Wu, Z., Meng, H. M., and Cai, L. (2007). "Facial expression synthesis using pad emotional parameters for a chinese expressive avatar."In International Conference on Affective Computing \& Intelligent Interaction.

Conflict of Interest: The authors declare that the research was conducted in the absence of any commercial or financial relationships that could be construed as a potential conflict of interest.

Publisher's Note: All claims expressed in this article are solely those of the authors and do not necessarily represent those of their affiliated organizations, or those of the publisher, the editors and the reviewers. Any product that may be evaluated in this article, or claim that may be made by its manufacturer, is not guaranteed or endorsed by the publisher.

Copyright $\odot 2021$ Jiang, Meng and Ji. This is an open-access article distributed under the terms of the Creative Commons Attribution License (CC BY). The use, distribution or reproduction in other forums is permitted, provided the original author(s) and the copyright owner(s) are credited and that the original publication in this journal is cited, in accordance with accepted academic practice. No use, distribution or reproduction is permitted which does not comply with these terms. 